This item was submitted to Loughborough's Research Repository by the author.

Items in Figshare are protected by copyright, with all rights reserved, unless otherwise indicated.

\title{
Formation of twins in AION material and its effects on the Vickers hardness and fracture toughness
}

PLEASE CITE THE PUBLISHED VERSION

https://doi.org/10.1016/j.ceramint.2019.07.089

PUBLISHER

Elsevier

VERSION

AM (Accepted Manuscript)

\section{PUBLISHER STATEMENT}

This paper was accepted for publication in the journal Ceramics International and the definitive published version is available at https://doi.org/10.1016/j.ceramint.2019.07.089.

LICENCE

CC BY-NC-ND 4.0

\section{REPOSITORY RECORD}

Ding, Maomao, Tun Wang, Benjamin Maerz, Stuart Robertson, Zehan Sun, Lingcong Fan, Ying Shi, and Houzheng Wu. 2019. "Formation of Twins in Alon Material and Its Effects on the Vickers Hardness and Fracture Toughness". figshare. https://hdl.handle.net/2134/38292. 


\section{Accepted Manuscript}

Formation of twins in AION material and its effects on the Vickers hardness and fracture toughness

Maomao Ding, Tun Wang, Benjamin Maerz, Stuart Robertson, Zehan Sun, Lingcong Fan, Ying Shi, Houzheng Wu

PII:

$$
\text { S0272-8842(19)31907-8 }
$$

DOI: https://doi.org/10.1016/j.ceramint.2019.07.089

Reference: CERI 22204

To appear in: Ceramics International

Received Date: 27 June 2019

Revised Date: 5 July 2019

Accepted Date: 8 July 2019

Please cite this article as: M. Ding, T. Wang, B. Maerz, S. Robertson, Z. Sun, L. Fan, Y. Shi, H. Wu, Formation of twins in AION material and its effects on the Vickers hardness and fracture toughness, Ceramics International (2019), doi: https://doi.org/10.1016/j.ceramint.2019.07.089.

This is a PDF file of an unedited manuscript that has been accepted for publication. As a service to our customers we are providing this early version of the manuscript. The manuscript will undergo copyediting, typesetting, and review of the resulting proof before it is published in its final form. Please note that during the production process errors may be discovered which could affect the content, and all legal disclaimers that apply to the journal pertain. 


\title{
Formation of Twins in AlON Material and its Effects on the Vickers Hardness and Fracture Toughness
}

Maomao Ding ${ }^{\mathrm{a}}{ }^{\mathrm{b}}$, Tun Wang ${ }^{\mathrm{a}}$, Benjamin Maerz ${ }^{\mathrm{b}}$, Stuart Robertson ${ }^{\mathrm{b}}$, Zehan Sun ${ }^{\mathrm{a}}$, Lingcong Fan ${ }^{\mathrm{a}}$, Ying Shi ${ }^{\mathrm{a}^{*}}$, Houzheng $\mathrm{Wu}^{\mathrm{b}^{*}}$

${ }^{a}$ School of Materials Science and Engineering, Shanghai University, Shanghai, 200444, China

b Department of Materials, Loughborough University, Leicestershire, LE11 3TU, United Kingdom

\section{Correspondence:}

Ying Shi, School of Materials Science and Engineering, Shanghai University, Shanghai, China. Email: Yshi@ shu.edu.cn.

Houzheng $\mathrm{Wu}$, Department of Materials, Loughborough University, Leicestershire, United Kingdom. Email: H.Wu2@lboro.ac.uk.

\begin{abstract}
Aluminum oxynitride $(\gamma$-AlON $)$ powders were synchronously synthesized by carbothermal reduction-nitridation (CRN) and high-temperature solid state reaction (SSR) methods. Twin structures existing in $\gamma$-AlON powders and transparent $\mathrm{AlON}$ ceramics were investigated by systematically employing electron backscattered
\end{abstract}


diffraction (EBSD) and transmission electron microscopy (TEM). It was found that the twin structures in synthetic powder and transparent ceramics exhibit quite different microstructural features; binary twin structures were widely observed in powders and ceramics, whereas the sandwich-like twin structure was produced only in transparent ceramics. High-resolution electron backscattered diffraction (HREBSD) was used to determine the residual elastic stress distributions in AlON powders and ceramics. Discrepancies in the magnitude and distribution of the residual stress between binary twins and sandwich-like twins were fully clarified. The formation of two kinds of twins in powders and ceramics was discussed in detail. The Vickers hardness and its corresponding indentation size effect (ISE) were studied in CRN-AlON and SSR-AlON ceramics. The effects of the twin structure on the Vickers hardness and fracture toughness were investigated simultaneously.

Keywords: $\gamma$-AlON, Twin structure, Vickers hardness, Fracture toughness.

\section{Introduction}

Aluminum oxynitride $(\gamma-\mathrm{AlON})$ materials are recognized to exist as a solid solution of $\mathrm{AlN}$ and $\mathrm{Al}_{2} \mathrm{O}_{3}$, which have been widely investigated over the last 20 years [1,2]. Owing to its excellent thermal and chemical 
stability, extremely high optical transmission from the ultraviolet to mid-infrared wavelength region, outstanding strength, hardness and friction resistance, spinel $\gamma$-AlON is considered a promising transparent window material for armor [3,4]. $\gamma$-AlON phased powders have been synthesized by the carbothermal reduction nitridation (CRN) method [5], high-temperature solid-state reaction (SSR) [6,7], aluminothermic reduction method [8] and sol-gel nitridation method [9]. The SSR and CRN procedures are thought to be the most economical and practical approaches to fabricate $\gamma$-AlON. Great efforts have been undertaken to elucidate the microstructural evolution of AlON powders and ceramics during their synthesis and densification processing [10-12].

Twins in AlON ceramics have been discovered and explored in recent years by many researchers [13-17]. Paliwal [13] first noted the presence of a twin structure in AlON compressed under controlled planar confinement by using the HRTEM technique. Clayton and McCauley [14] developed a nonlinear thermomechanical mode for AlON and predicted the twinning stress in the $\{111\}$ plane. An experiment by Wang $[15,16]$ regarding the effects of sintering additives in the twin fraction was used to study and directly observe the existence of twin lamellas via electron backscattered diffraction (EBSD). Recently, the strengthening mechanism of twin lamellas in AlON ceramics was demonstrated [17]. EBSD is an effective microstructural characterization technique that has 
been widely used in materials science, engineering and geology, especially involving metals and alloys. The essential concept of the EBSD technique is the collection of diffraction patterns produced by backscattered electrons across a polished sample surface. The obtained Kikuchi patterns can be automatically indexed by commercial software packages to acquire detailed information such as the phase distribution and crystal orientation. Given the strong performance of EBSD technology, various EBSD-based techniques have been exploited and applied to material characterization. Troost [18] first introduced high-resolution electron backscatter diffraction (HREBSD). Then, Wilkinson, Meaden and Dingley (WMD) [19-23] improved and provided a detailed description of this technique based upon earlier work. Cross-correlation-based analysis of EBSD patterns was innovatively proposed, which allowed small shifts in pattern features to be quantified and expressed in the displacement gradient tensor. From these values, variations in the elastic strain and lattice rotation could be calculated by comparing the pattern shifts at the sample surface relative to a reference pattern. By employing HREBSD, Abdolvand [24] demonstrated the presence of highly concentrated residual stress, lattice rotation and dense dislocations close to twin tips in zircaloy. Vickers hardness $\left(\mathrm{H}_{\mathrm{V}}\right)$ testing is a widespread means of measuring hardness and fracture toughness. Previous investigations [25] identified that the calculated hardness was 
load-dependent, usually exhibiting a drop in hardness with increasing load. Such a phenomenon was believed to be an indentation size effect (ISE). A proportional specimen resistance (PSR) mode was proposed by Li and Bradt [26] to explain the ISE. The PSR model was divided into two parts related to the damage resistance and load-independent hardness. Due to the low requirements of sample preparation and almost no restrictions on sample size, the Vickers indentation fracture (VIF) technique was employed to resolve the fracture toughness $\left(\mathrm{K}_{\mathrm{IC}}\right)$ corresponding to the critical stress intensity factor. The VIF model was developed in amorphous glass and is an indentation-based technique; thus, care must be taken when comparing the indentation-based fracture toughness to the notched beam fracture toughness and when comparing different ceramics.

Although several meaningful research papers about the twins in AlON have been published, the formation of the twin and its detailed effects are still not uncovered. In this work, the twins in AlON powders and ceramics were investigated by using a focused ion beam (FIB) system, conventional EBSD and TEM techniques. Through incorporation of the HREBSD technique, the residual elastic stress distribution and formation of twins were revealed. Based on the determination of the Vickers hardness and fracture toughness of AlON, the effects of twins on the hardness and fracture toughness were studied simultaneously. 


\section{Experimental Procedures}

$2.1 \gamma$-AlON powder synthesis and ceramic manufacturing

$\gamma$-AlON powders were synthesized through a high-temperature solid-state reaction (SSR) and carbothermal reduction nitridation (CRN) method. For the solid-state reaction, the starting solid materials were $\gamma-\mathrm{Al}_{2} \mathrm{O}_{3}$ (with an average particle size of $\sim 100 \mathrm{~nm}$, Shanghai Fenghe Ceramics Co. Ltd. Shanghai, China) and AlN (with an average particle size of $\sim 580 \mathrm{~nm}$, Tokuyama Soda Co. Ltd., Tokuyama, Japan). The $\gamma-\mathrm{Al}_{2} \mathrm{O}_{3}(65 \mathrm{~mol} \%)$ and $\mathrm{AlN}(35 \mathrm{~mol} \%)$ were weighed and mixed in a polytetrafluoroethylene (PTFE) jar with anhydrous ethanol and dispersant (PVP K-30, Aladdin Biochemical Technology Co. Ltd., Shanghai). The mixture was ball milled together with spherical alumina balls $(\sim 5 \mathrm{~mm}$ and $\sim 10 \mathrm{~mm}$ ) as the milling medium. The ball milling was accomplished on planetary ball-milling equipment at a rotating speed of $250 \mathrm{rpm}$ for 12 hours. The well-dispersed slurry was dried in an oven at $80 \square$ for 24 hours and then passed through a 200-mesh nylon sieve to eliminate large agglomerates. Then, the precursors were loaded in alumina crucible covered by an alumina lid and heated in a muffle furnace to $400 \square$ with a dwell time of 6 hours to remove the residual solvent and PVP. The alumina crucible with the precursors was then transferred to a high-temperature sintering furnace equipped with a graphite crucible and graphite heating unit. The precursors were heated up to $1750 \square$ with a 
dwell period of 4 hours in a flowing nitrogen atmosphere, followed by a cooling rate of $10 \square / \mathrm{min}$. Almost the same experimental procedures were applied to the CRN method. Carbon black (5.3 wt $\%$ ) was used instead of AlN. After calcination at $1750 \square$ for 4 hours in the following nitrogen atmosphere, the alumina crucible with the as-synthesized AlON powder was transferred to a muffle furnace. The residual carbon was eliminated after heating at $600 \square$ with a dwelling time of 10 hours.

The AlON ceramics were manufactured through pressureless sintering in this work. First, two kinds of as-synthesized AlON powders were separately dispersed in anhydrous ethanol and broken into submicron particles in alumina jar by ball milling at $300 \mathrm{r} / \mathrm{min}$ for 24 hours. The primary purpose of this step is to improve the homogeneity of particle size and sintering activity. Then, $0.4 \mathrm{wt} \% \mathrm{MgO}$ and $0.1 \mathrm{wt} \%$ $\mathrm{Y}_{2} \mathrm{O}_{3}$ were added as sintering additives. After a second ball milling step for 12 hours, the pastes were dried in an oven at $80 \square$ for 24 hours. A 200-mesh nylon sieve was used to eliminate agglomerates. The as-sieved powders were filled in a metal die with an inner diameter of $20 \mathrm{~mm}$. After isostatic pressing at $200 \mathrm{MPa}$ for $10 \mathrm{~min}$, columnar powder biscuits were obtained. For densification, specific steps are stated here. First, the as-manufactured powder biscuits were embedded with boron nitride powders in a boron nitride crucible. Then, the boron nitride crucible was transferred to a high-temperature sintering furnace (ZT-50-20, Chenghua 
Co., Ltd., Shanghai, China). Subsequently, the furnace was pumped down to $\sim 1 \mathrm{E}-3 \mathrm{~Pa}$ to remove the absorbed gases. Second, flowing nitrogen was turned on at the beginning of heating. The typical heating rate was $\sim 1 \square / \mathrm{min}-\sim 5 \square / \mathrm{min}$. A dwelling period of 24 hours was then set to achieve densification when the temperature reached $1900 \square$. Finally, the furnace was cooled down to $1000 \square$ with a cooling rate of $\sim 5 \square / \mathrm{min}$ and then naturally cooled down to room temperature. To date, AlON ceramics have been fabricated in this way by using two kinds of AlON powders.

2.2 Sample preparation for hardness and microscopy characterization

The as-fabricated AlON powders and ceramics were mixed with phenolic hot mounting resin with carbon filler. Then, cylindrical blocks were fabricated by electrohydraulic hot-mounting pressing (CitoPress-5, Struers, Cleveland, USA) and polished by using Struers diamond suspension, starting from a grit size of $9 \mu \mathrm{m}$, then $3 \mu \mathrm{m}$, followed by 1 $\mu \mathrm{m}$ at the finish step. For surfaces examined with EBSD, a further polish was applied by using a colloidal silica suspension with a grit size of 0.4 $\mu \mathrm{m}$ (Buehler, Illinois, USA).

TEM samples were prepared by using a dual-beam focused ion beam (FIB) microscope (Nova 600 Nanolab, FEI, USA) equipped with a backscattered electron (BSE) detector. Detailed liftout procedures are given here. The surface of the samples was coated with a carbon layer with a thickness of $\sim 20 \mathrm{~nm}$ before being placed in the FIB tool 
(Q150T ES Plus, Quorum Technologies Ltd, UK) in order to enhance the electrical conductivity of the sample surface while not inhibiting the EBSD signal. The twins existing in the AlON powders and ceramics were identified under BSE mode. Subsequently, a platinum layer with a thickness of $\sim 2 \mu \mathrm{m}$ was deposited on the selected location in order to protect the surface from ion damage and contamination. Staircase cuts at a voltage of $30 \mathrm{keV}$ and beam current of $20 \mathrm{nA}$ were then carried out on either side of the selected region, and then the sample was further thinned to a thickness of $\sim 1 \mu \mathrm{m}$ with gradually reduced currents. The cross-sectional slices were lifted out and placed on a copper grid using a micromanipulator. After thinning at a tilt angle of $\pm 1.5^{\circ}$ with successively lower currents ( $1 \mathrm{nA}$ to $100 \mathrm{pA}$ ), the slice was thinned down to $\sim 100 \mathrm{~nm}$ for TEM examination. When HRTEM imaging was required, the slices were further thinned with an extremely low current ( $60 \mathrm{pA})$. The typical thickness of the final slices was $\sim 50 \mathrm{~nm}$, which is sufficiently electron transparent for HRTEM.

\subsection{Vickers indentation measurement}

A Vickers indenter (DuraScan-50, Struers, Cleveland, USA) at loads of 0.01-10 kgf was employed to execute indents. The loading, holding and unloading times were $10 \mathrm{~s}, 10 \mathrm{~s}$ and $5 \mathrm{~s}$, respectively. Five different loads ranging from $0.5 \mathrm{kgf}$ to $10 \mathrm{kgf}$ were selected for indentation testing. To ensure the accuracy of the hardness measurements, at least 5 indents 
were made at each load. The as-produced indentations were imaged by

SEM. The hardness $\left(\mathrm{H}_{\mathrm{V}}\right)$ of the specimen was calculated by using the following equation:

$$
\mathrm{H}=\mathrm{K} \frac{P}{d^{2}}
$$

where $\mathrm{K}$ is a constant contingent on the indenter shape, which is 1.8544 for the Vickers indenter; $\mathrm{P}$ is the indentation load in newtons; and $\mathrm{d}$ is an average of two diagonal lengths for each indentation. Since the hardness measurement is performed under a certain range of loads, the indentation size effect (ISE) can be determined using Meyer's law:

$$
\mathrm{P}=\mathrm{A} d^{n}
$$

The constant A and Meyer's n can be acquired from regression analysis. Due to the absence of $n=2$, a proportional specimen resistance (PSR) model proposed by $\mathrm{Li}$ and Bradt [26] was employed, fitting the true hardness.

$$
\mathrm{P}=a_{1} \mathrm{~d}+a_{2} d^{2}
$$

where constants $a_{1}$ and $a_{2}$ generally indicate the possibility of cracking introduced by indentation and the resistance of crack-free plastic deformation, respectively [27-29].

The Vickers indentation fracture (VIF) toughness was calculated based on the following equation:

$$
K_{I C}=0.016\left(\frac{E}{H}\right)^{1 / 2} \times \frac{P}{c^{3 / 2}}
$$

where $K_{I C}$ is the fracture toughness, $\mathrm{E}$ is the Young's modulus, $\mathrm{H}$ is the 
hardness in GPa and $\mathrm{c}$ is the distance from the tip of the crack originating from the corner of the indentation to the center of the indentation impression.

\subsection{Microstructure Characterization}

A field emission gun scanning electron microscope (FEG-SEM, JMS-7800F, JEOL, Tokyo, Japan) equipped with a backscattered electron (BSE) detector (SM84030SRBE, Joel, Tokyo, Japan) and electron backscattered diffraction (EBSD) detector was employed. Conventional SEM images were acquired under a voltage of $5 \mathrm{keV}$ and a probe current of $8 \mathrm{nA}$. BSE images were captured at an accelerating voltage of $10 \mathrm{keV}$ with a probe current of $12 \mathrm{nA}$, and these parameters were optimized for identifying interface boundaries. The SEM and BSE images were processed by using the image analysis software ImageJ (NIH, USA).

EBSD maps were obtained with a working distance of $10 \mathrm{~mm}$ under a voltage and probe current of $20 \mathrm{keV}$ and $15 \mathrm{nA}$, respectively. Different step sizes were applied for the conventional EBSD and high resolution EBSD analysis. For HREBSD, the unprocessed Kikuchi patterns without gain applied were saved at each step point. The EBSD data were then processed with OIM Analysis ${ }^{\mathrm{TM}}$ software (EDAX Inc., America), and the Euler angles of each step point were obtained. The unprocessed Kikuchi patterns were processed using CrossCourt 4 (BLG Productions Ltd. \& Vantage Software Inc.), which adopts cross-correlation-based techniques 
to measure the relative shifts between EBSD patterns caused by small lattice rotations or elastic strains. Detailed procedures are given here. First, the EBSD patterns were transferred from the data collection software OIM Analysis ${ }^{\mathrm{TM}}$ and loaded in CrossCourt 4. The material properties, especially the elastic coefficients, were then inputted into the software. Here, the elastic coefficients $\mathrm{C} 11, \mathrm{C} 12$ and $\mathrm{C} 44$ were taken as $377 \mathrm{GPa}, 133 \mathrm{GPa}$ and $125 \mathrm{GPa}$, respectively [30]. Once the material properties were all inputted, the threshold filter of kernel average misorientation (KAM) was applied. The data above the threshold of $5 \times$ $10^{-3}$ were excluded, eliminating the poor-quality or low-confidence patterns. Subsequently, patterns with the best criteria value for each grain were chosen as references, which were selected from zero-strain and highest-quality regions. In fact, it is impossible to identify where a region of zero strain is. Therefore, we used existing measures from the KAM data as criteria to identify points that were the most promising reference candidates. In this way, a series of references were selected that together covered all of the grain. Next, a minimum of 4 regions of interest (ROIs) were needed to calculate the distortion tensor. Typically, 40 ROIs with a size of $128 \times 128$ pixels were used to oversample, and the best fit distortion tensor was calculated. The distribution of the 40 ROIs was that the first ROI was always placed in the center of the pattern, with 19 others arranged in a circle around it. The other 20 ROIs were randomly 
assigned on the Kikuchi patterns. Following fast Fourier transformation (FFT), the ROIs were transformed to the Fourier domain. Finally, low-frequency and high-frequency cutoff filters were applied to remove the background and noise, which were optimized at 7 and 28, respectively, for the obtained Kikuchi patterns. Next, the cross-correlation processing based on the work of WMD was performed. Ultimately, an arrangement of maps such as elastic strain maps (normal \& shear strains), rotation tensor maps (rigid body rotations), elastic stress maps and quality maps could be obtained.

The structural features of twins were examined at higher resolution with a transmission electron microscope (F20 G2, FEI, Tecnai). The characterization was presented in the following formats: conventional TEM images, selected-area electron diffraction (SAED) patterns and high-resolution transmission electron microscopy (HRTEM) images. The TEM images were processed by using the DigitalMicrograph software.

\section{Result and Discussion}

\subsection{Twins in synthetic AlON powders}

As shown in Fig. 1, the single phased AlON powders were synthesized by CRN and SSR method. The microstructures of the synthetic AlON powders are displayed in Fig. 2. Visible growth terraces with different growth directions were observed in two kinds of AlON 
powders. Such terraces were caused by the gas reaction during the powder synthesis process, which has already been investigated in detail [31]. Due to the highly symmetrical face-centered cubic (FCC) crystal structure of AlON, the grains usually grow in preferential orientations. To determine the orientations in AlON powders, the powders were mixed with hot mounting resin and then finely polished. A series of characterizations was carried out on the cross sections of the powders.

Fig. 3 (a) and (c) shows the cross-sectional BSE images of as-polished SSR and CRN powder with high-magnification images inserted. A favorable contrast difference is observed in one particle, as presented in the embedded images. BSE imaging provides channeling contrast, which allows the identification of the twins and twin boundaries. To distinguish from the contrast difference caused by agglomeration, electron backscatter diffraction (EBSD) analysis was used to obtain the orientation of each grain in the form of the Euler angle. The Euler maps of the SSR-AlON and CRN-AlON powders, with average grain sizes of 7.21 $\pm 0.79 \mu \mathrm{m}$ and $5.59 \pm 0.84 \mu \mathrm{m}$, respectively, are shown in Fig. 3 (b) and (d). The misorientations of the red square grains are listed in Table 1 by processing the Euler angle of each grain. These misorientations can be classified into random orientation and special preferred misorientation $\left(<111>/ 60^{\circ}\right)$, which are believed to represent agglomeration and twins, respectively. This preferred misorientation, usually emerging in FCC 
metals such as copper, can also be expressed as $\{111\}<112>$. It is known that the $\{111\}$ plane is the close-packed plane in the FCC crystal structure, which possesses maximum interplanar spacing and minimum plane energy. Once there are different growth directions, the grains are likely to form twins with twin planes $\{111\}[14,32-33]$. In this way, the energy required in the powder synthesis system can be relatively low.

To better understand the microstructure of twins, a transmission electron microscope was utilized. Fig. 4 (a) shows the BSE image of the powder of interest, which was already identified as containing twins by using EBSD. The twin boundary can be clearly observed. Then, a Pt layer with a thickness of $2 \mu \mathrm{m}$ was deposited on the surface of the region we selected. The TEM sample was lifted out for further analysis in the FIB tool. The lamina obtained by stair-like cutting is displayed in Fig. 4 (b). After thinning down to $\sim 50 \mathrm{~nm}$, TEM analysis was carried out, and conventional bright field (BF) TEM images were obtained, as shown in Fig. 4 (c) and (d). Many stress fringes were present in the TEM foil. These stress fringes may have been generated when the sample was thinned down for HRTEM. Fig. 4 (e) and (g) shows the HRTEM images of red and yellow dashed square regions in Fig. 4 (d). The clear lattice stripes of the twin boundary and grain domains are illustrated. The lattice is divided into two completely symmetric parts by the twin boundary in Fig. 4 (e). SAED patterns of selected regions are embedded in the 
HRTEM images. The SAED of the twin boundary was calibrated with a pair of mirrored periodic lattices. The calibrated lattices matched the diffraction pattern of AlON with the [011] zone axis. These results visually display the microstructure of the twin boundary and reconfirm that the twin plane is $\{111\}$. Subsequently, fast Fourier transformation (FFT) processing was applied to the HRTEM images using DigitalMicrograph software. A pair of symmetrical masks was applied on the interface $[\overline{1} 1 \overline{1}]$. The corresponding inverse fast Fourier transform (IFFT) images are presented in Fig. 4 (f) and (h), showing the dislocation defects that were labeled with " $T$ ". The dislocation density within the twin boundary region, which was calculated by dividing the dislocation quantity by the total area, was approximately $6.023 \times 10^{15} \mathrm{~m}^{-2}$. In contrast, there were nearly no defects in the area away from the twin boundary. Such a difference could be attributed to several factors. First, the dislocations could effectively contribute to the formation of a perfect coherent twin boundary, which has the lowest energy and most stable state. Considering that the twin boundary would also resist dislocation glide, the dislocations will pile up along the twin boundary [34-36].

Combining our experimental results and previous works, it is inferred that the formation process of twins in $\mathrm{AlON}$ powders is as follows: The first step is the nucleation of AlON consisting of a series of solid-solid, gas-solid and gas-gas reactions. Subsequently, inconsistencies 
in the grain growth direction open up the possibility of twin formation with a twin plane and growth direction of $\{111\}$ and [112], respectively. This mechanism is considered to be the least energy-consuming method. In this way, the grain grew and finally stabilized.

\subsection{Twins in AlON ceramics}

Fig. 5 shows the Euler + band contrast maps of the polished surface of CRN-AlON and SSR-AlON ceramics sintered at $1900{ }^{\circ} \mathrm{C}$ with a dwell time of 24 hours. Fig. 5 (a) and (c) illustrate the CRN-AlON ceramics without and with sintering additives added, and (c) and (d) present the SSR-AION ceramics without and with sintering additives added. The addition of sintering aids significantly increases the density of ceramics, greatly enhancing the elimination of pores. In addition to the binary twin structure that existed in the AlON powders, new types of sandwich-like twins (STs) were observed in densified AlON ceramics, as shown in the yellow dashed squares in Fig. 5. The Euler angles of the selected grains and misorientations are shown in Table 2. As expected, the sandwich-like twins (STs) have the same misorientation values as the binary twins (BTs) in the powders. It is worth mentioning that there is just one twin layer in STs since the twin nucleation energy is higher than the resistance of twin growth in AlON materials $[14,33]$. Namely, the twins tend to grow rather than form new twins.

Two types of twin densities (number of twins per unit area) were 
calculated and are listed in Table 3. It is advantageous that the addition of sintering aids reduced the ST density obviously and had almost no effect on the BT density. A comparison of the upper and lower parts of Fig. 5 indicates that the thickness of the twin lamella decreased simultaneously. The reasons for the formation and variation of the twins in AlON ceramics were studied in the following discussion.

The formation of twins is not only related to the essential properties of the material but is also affected by internal or external factors, such as tensile stress. In this work, it is easy to understand that binary twins originate from the twins in the powders. The formation of sandwich-like twins is generally believed to be caused by excessive local stress, which must be higher than the twining stress of materials such as FCC metals and alloys. Twinning can efficiently release the undesirable excessive stress. Because pressureless sintering was used, we need to consider only the influence of the internal stress generated during the sintering process. From the perspective of the twin density, two main affecting factors are the grain size and local stress [33,37-40]. The average grain sizes processed by OIM Analysis ${ }^{\mathrm{TM}}$ are also shown in Table 3. Considering that dimensional changes are not particularly noticeable, the results indicate that grain size effects are not the dominant factor in our experiments. In other words, the decrease in the twin density is likely caused by the decline of the internal stress. Moreover, the relationship between twin 
lamella thickness and stress has been shown to be positively correlated [33]. The variation of the lamella thickness in our work is in good agreement with this relationship.

To elucidate the relationship between internal stress and twin formation, high-resolution EBSD (HR-EBSD) was used. The HR-EBSD maps of binary twins in powders, binary twins in ceramics and sandwich-like twins in ceramics are presented in Fig. 6, Fig. 7 and Fig. 8, respectively. The layout of Figs. 6-8 is the same and detailed as follows: ( $\square$ ) the top row gives an inverse pole figure (IPF) of the twins of interest in the AlON powder and ceramics, kernel average misorientation (KAM) in radians, and image quality maps with reference points marked with black spots are presented; $(\square)$ the bottom row shows the maps of the elastic stress as calculated using infinitesimal strain theory, consisting of the normal stress $\left(\delta_{11}, \delta_{22}, \delta_{33}\right)$ on the diagonal, the shear stress $\left(\delta_{12}, \delta_{31}\right.$, $\left.\delta_{23}\right)$ on the off diagonal positions and the von Mises stress distributions in the bottom left. The $\delta_{33}$ term is set to zero in calculating the hydrostatic strain. Tension is shown as red as a default, and compression is shown in blue. The values are all in GPa; here, the sample axes 1,2 and 3 are defined by default as horizontal (to the right), vertical (up the map) and normal (out of the surface), respectively. For example, the $\delta 23$ shear stress describes a shear stress from the 2 axis into the 3 axis as positive (red) and the opposite as negative (blue). The same axes apply to the 
other stress maps displayed in this work.

From Fig. 6 (d) and (f), the higher relative stress concentrates at the edge of the powder from Fig. 3 (b), possibly caused by incomplete polishing when the powder morphology changes at the edge of the powder. At the same time, the holes in the grain resulted in higher relative concentrations. However, there is no obvious law about twins and relative stresses. Then, relative stress maps of the binary twin, which are generally considered to be inherited from powders in AlON ceramics, are illustrated in Fig. 7 (d). In view of the normal stresses, the residual stress is evenly distributed in the grain. Regarding the shear stress, the higher stress concentration is located at the grain boundary and junctions of the grain boundary. Such residual stress as an internal stress around the grain boundary may be ascribed to distortion of the atomic arrangement and the piled up defects, such as dislocations at grain boundaries. However, there is no difference in stress, regardless of normal stress or shear stress, near the domains of the twin boundary. The equivalent stress of the binary twin is shown as the Von Mises stress map in Fig. 7 (d). The Von Mises stress as the equivalent stress can only express the magnitude of stress irrespective of a positive or negative sign. Obviously, the distribution of residual stress in this binary twin system was mainly concentrated at the region of grain boundary, especially in the region of boundary junction. Hence, there is still no clear evidence to explain why the residual stress is 
related to the twin structure.

Fig. 8 (d) presents the elastic stress maps of sandwich-like twins as described above. First presented are the results of normal stress shown in the diagonal of Fig. 8 (d). In addition to the high stress concentrations near the grain boundaries mentioned above, the inhomogeneous stress is distributed inside the twin, which is completely different from the case of binary twins in powders and ceramics. Specifically, the grain is divided into three parts by twin lamella, which are named matrix 1 (M1), twin and matrix 2 (M2) from left to right. An extremely high stress concentration compared with the values in Fig. 6 and Fig. 7 exists at the top of M1 and gradually increases from the top to the bottom. The opposite distribution appears in M2. Namely, the stress with an almost equivalent concentration in M1 is presented at the bottom of M2 and gradually decreases from the bottom to top. In this way, the distribution of stress inevitably produces shear stress in the direction parallel to the normal stress axis, which is vertical to the sample surface. As shown in the shear stress maps, a similar distribution can be observed in the image of $\delta_{23}$. On both sides of the twin boundary, the concentration of $\delta_{12}$ and $\delta_{31}$ is relatively high even if it is much lower than the maximum normal stress. From the equivalent stress of the system shown in the Von Mises stress map, there is a large amount of residual stress remaining in the ST system. This kind of residual stress exists in the form of shear stress. 
By comparing Fig. 6, Fig. 7 and Fig. 8, the residual stresses of binary twins in ceramics are found to be consistent with those in powders, whether in the distribution or magnitude. Obvious shear stress, which is much larger than that in binary twins, remains in the sandwich-like twins, which exist only in ceramics. Thus far, combining previous research and this work, we conclude that the formation of STs was driven by excessive stress produced during sintering. Although the twinning of AlON grains releases excessive stress that is greater than the twinning stress of the AlON material and formed sandwich-like twins, the residual stress inevitably affects the performance of $\mathrm{AlON}$ ceramics, especially in mechanical properties. In addition, the thickness of the twin layer is associated with the local internal stress as well. Therefore, the addition of sintering additives has a significant effect in reducing internal stress. Although a large number of studies have used yttrium oxide and magnesium oxide as sintering aids, the specific mechanism is yet to be fully understood. Here, we propose a hypothesis that the addition of sintering aids, especially magnesium oxide, provides a partial liquid environment during AlON ceramic sintering. It is generally known that the internal stress in the sintering system with a liquid phase is much lower than that without it. Of course, the roles of sintering aids are definitely not restricted to reducing internal stress and need to be studied in further detail. 


\subsection{Vickers hardness and VIF toughness of AlON ceramics}

Due to the porosity and poor compactness of the sintered ceramics without sintering additives, as shown in Fig. 5 (a) and (b), the hardness test was carried out on the ceramics with $\mathrm{MgO}$ and $\mathrm{Y}_{2} \mathrm{O}_{3}$ added. Fig. 9 graphically depicts the Vickers hardness for CRN-AlON and SSR-AlON with a relative density exceeding $99.5 \%$, as determined by Eq. (1) under varying loads. Here, each plotted data point in the hardness-load curves is the average value of 5 indentation measurements. It is clear that the CRN-AlON exhibited a markedly higher hardness than the SSR-AION. The hardness decreased with increasing load in both curves, showing a similar nonlinear trend. The synchronous reduction in hardness explicitly indicates the presence of an indentation size effect (ISE). The factors defined in Eq. (2) and (3) were quantified by employing Mayer's law and the PSR model and are expressed in Table 4. The exponents $n$ in Meyer's law for the CRN-AlON and SSR-AION ceramics were 1.857 and 1.844, respectively. Therefore, both AlON ceramics exhibit an ISE effect, and SSR-AION has an enhanced ISE due to the lower $n$ values. In the PSR model, there are divergences in $\mathrm{a}_{1}$ and $\mathrm{a}_{2}$ between CRN-AION and SSR-AlON. A previous theory reported by Quinn [28] postulated that $\mathrm{a}_{1}$ represents the influence of the cracks underneath and around the indentation impression in the ISE. The larger $a_{1}$ values correspond to a greater possibility of crack formation and propagation when the indenter 
is pressed down. As presented in the rightmost of Table 4, the load-independent hardness $\left(\mathrm{H}_{\mathrm{PSR}}\right)$ of $\mathrm{CRN}-\mathrm{AlON}$ was higher than that of SSR-AlON. Such a difference is well-aligned with the experimental hardness value. As noted by Rice [41], such variation between two ceramics may be caused by the grain size. Considering the negligible grain size difference in our work, the effects of the grain size in the Vickers hardness may be marginal. As indicated by Table 3, the twin density in CRN-AlON ceramics is over $50 \%$ higher than that in SSR-AlON ceramics. Reasonably, we can attribute such a difference in hardness to the twin density. The twin boundary may play a similar role as the grain boundary, efficiently reducing the grain size and enhancing the hardness in what is known as the Hall-Petch relationship [42-43]. In our previous work [44], we found that the fracture strength of the twin boundary is higher than that of the grain boundary. We reach the favorable conclusion that the presence of twins increases the hardness without damage to other strengths of materials.

The lengths of radial cracks produced under each load were measured. The Vickers indentation fracture (VIF) toughness was then calculated by using Eq. (4) at each load. Fig. 10 shows the calculated VIF toughness as a function of the crack length for CRN-AlON and SSR-AlON. Comparing two VIF toughness curves, we find a noticeable divergence in the crack length when the same force was loaded on both 
ceramics. The greater the force, the more obvious the difference is. Such a difference indicates that the resistance of crack propagation in CRN-AlON is greater than that in SSR-AlON. Moreover, both curves suffer a drop initially and then increase when the crack length increases from $100 \mu \mathrm{m}$ to approximately $140 \mu \mathrm{m}$. Namely, the inhibitory effect of crack propagation was sharply enhanced when the crack was greater than $100 \mu \mathrm{m}$, which was similar to the case of the average grain size. To reveal the resistance mechanism, the morphology of radial cracks was captured and is shown in Fig. 11. Fig. 11 demonstrates the representative behaviors of crack propagation, deflection and resistance at AlON grain and twin boundaries. More specifically, radial cracks propagated from the indentation impression and were then constrained and deflected at the grain and twin boundaries, as indicated by yellow and red arrows, respectively. The reason for the deflection, whether at the grain boundary or twin boundary, was generally ascribed to the mismatch of the slip system. The cracks were constrained and propagated along the twin, and the grain boundary was influential as the crack propagated along the lower toughness resistance paths. Therefore, the deflection and restraint effects at the grain and twin boundaries dominated the resistance for crack propagation. Based on this result, the main reason for the greater resistance in CRN-AlON was the presence of the higher twin density. When the crack length is greater than the average grain size, not only will 
the twin boundary inhibit its further expansion but also will the grain boundary have the same effect. In summary, twin boundaries play a similar role again with grain boundaries in preventing the generation of long cracks and enhancing toughness.

\section{Conclusion}

$\gamma$-AlON powders were synthesized through carbothermal reduction nitridation (CRN) and high temperature solid-state (SSR) methods. Transparent AlON ceramics were fabricated by using synthetic CRN and SSR powders. The twin structure in synthetic AlON powders was innovatively investigated by applying EBSD to the polished cross section of powders. The preferred misorientation of twins was identified by high-resolution TEM and EBSD as $<111>/ 60^{\circ}$. Residual elastic stresses around the twin domain in powders and ceramics were determined by employing high-resolution EBSD. From the difference in the distribution of the residual stress, BTs in AlON ceramics were considered to originate from the twins in the powders. The formation of STs is related to local excessive shear stress. Moreover, the addition of sintering additives could reduce the ST density but had nearly no effect on the BT density in the two kinds of AlON ceramics. The CRN-AlON and SSR-AlON ceramics both suffer an indentation size effect in Vickers hardness. The twin boundaries both act as pseudo grain boundaries in the Vickers hardness 
test and VIF toughness analysis. Such pseudo grain boundaries may effectively decrease the grain size and enhance the toughness.

\section{Acknowledgment}

This work was supported by the National Natural Science Foundation of China (NO. 61475097).

\section{References}

[1] J.W. Mccauley, P. Patel, M. Chen, et al, AlON: A brief history of its emergence and evolution, J. Eur. Ceram. Soc. 29 (2009) 223-236.

[2] N.D. Corbin, Aluminum oxynitride spinel: A review, J. Eur. Ceram. Soc. 5(1989) 143-154.

[3] G.A. Gazonas, J.W. McCauley, I.G. Batyrev, et al., Multiscale Modeling of Armor Ceramics: Focus on AlON, Proceedings of the 27th Army Science Conference, 2011.

[4] L.M. Goldman, R. Twedt, Large-area ALON windows for reconnaissance and armor applications, Proc. Spie. 20097302.

[5] Y.W. Li, L.I. Nan, R. Yuan, Carbothermal reduction synthesis of aluminium oxynitride spinel powders at low temperatures, J. Mater. Sci. Lett. 16(1997) 185-186.

[6] J.W. Mccauley, N.D. Corbin, Phase relations and reaction sintering of transparent cubic aluminum oxynitride spinel (ALON), J. Am. Ceram. 
Soc. 62(2010) 476-479.

[7] G. Yamaguchi, H. Yanagida, Study on the reductive spinel - a new spinel formula $\mathrm{AlN}-\mathrm{Al}_{2} \mathrm{O}_{3}$ instead of the previous one $\mathrm{Al}_{3} \mathrm{O}_{4}$. Bull. Chem. Soc. Jpn. 32(1959) 1264-1265.

[8] Y. Wang, X. Xie, J. Qi, et al., Two-step preparation of AlON transparent ceramics with powder synthesized by aluminothermic reduction and nitridation method, J. Mater. Res. 29(2014) 2325-2331.

[9] S. Kikkawa, N. Hatta, T. Takeda, Preparation of aluminum oxynitride by nitridation of a precursor derived from aluminum-glycine gel and the effects of the presence of europium, J. Am. Ceram. Soc. 91(2008) 924-928.

[10] Y.C. Shan, Z.H. Zhang, X.N. Sun, Fast densification mechanism of bimodal powder during pressureless sintering of transparent $\mathrm{AlON}$ ceramics, J. Eur. Ceram. Soc. 36(2016) 671-678.

[11] M. Su, Y. Zhou, K. Wang, et al., Highly transparent AlON sintered from powder synthesized by direct nitridation, J. Eur. Ceram. Soc. 35(2015) 1173-1178.

[12] F. Chen, F. Zhang, J. Wang, et al., Preparation of $\gamma$-AlON transparent ceramics by pressureless sintering, Key Eng. Mater. 603(2014) 226-229.

[13] B. Paliwal, K.T. Ramesh, J.W. Mccauley, et al., Dynamic compressive failure of AlON under controlled planar confinement, J. Am. Ceram. Soc. 91(2008) 3619-3629. 
[14] J.D. Clayton, A Nonlinear Thermomechanical model of spinel ceramics applied to aluminum oxynitride (AlON), J. Appl. Mech. 78(2011) 011013.

[15] Z. Fang, C. Feng, H. Zhang, et al., Microstructure evolution in HIPed AlON and its effect on optical property, Opt. Mater. Express. $5(2015) 1682$.

[16] F. Chen, F. Zhang, J. Wang, et al., Microstructure and optical properties of transparent aluminum oxynitride ceramics by hot isostatic pressing, Scr. Mater. 81(2014) 20-23.

[17] H. Guo, J. Zhang, X. Mao, et al., Strengthening mechanism of twin lamellas in transparent AlON ceramics, J. Eur. Ceram. Soc. 38(2018) 3235-3239.

[18] K.Z. Troost, P. Vandersluis, D.J. Gravesteijn, Microscale elastic-strain determination by backscatter Kikuchi diffraction in the scanning electron-micro-scope, Appl. Phys. Lett. 62(1993) 1110-1112.

[19] A.J. Wilkinson, Measurement of elastic strains and small lattice rotations using electron back scatter diffraction, Ultramicroscopy. 62(1996) 237-247.

[20] A.J. Wilkinson, A new method for determining small misorientations from electron back scatter diffraction patterns, Scr. Mater. 44(2001) 2379-2385.

[21] M. Kamaya, A.J. Wilkinson, J.M. Titchmarsh, Measurement of 
plastic strain of polycrystalline material by electron backscatter diffraction, Nucl. Eng. Des. 235(2005) 713-725.

[22] A.J. Wilkinson, G. Meaden, D.J. Dingley, High-resolution elastic strain measurement from electron backscatter diffraction patterns: new levels of sensitivity, Ultramicroscopy. 106(2006) 307-313.

[23] A.J. Wilkinson, G. Meaden, D.J. Dingley, High resolution mapping of strains and rotations using electron backscatter diffraction, Mater. Sci. Technol. 22(2006) 1271-1278.

[24] H. Abdolvand, A.J. Wilkinson, Assessment of residual stress fields at deformation twin tips and the surrounding environments, Acta Mater. 105(2016) 219-231.

[25] J.B. Quinn, G.D. Quinn, Indentation brittleness of ceramics: a fresh approach, J. Mater. Sci. 32(1997) 4331-4346.

[26] H. Li, R.C. Bradt, The microhardness indentation load/size effect in rutile and cassiterite single crystals, J. Mater. Sci. 28(1993) 917-926.

[27] H. Li, R.C. Bradt, The effect of indentation-induced cracking on the apparent microhardness, J. Mater. Sci. 31(1996) 1065-1070.

[28] G. Quinn, P. Green, K. Xu, Cracking and the indentation size effect for Knoop hardness of glasses, J. Am. Ceram. Soc. 86(2003) 441-448.

[29] J. Wade, S. Ghosh, P. Claydon, et al., Contact damage of silicon carbide ceramics with different grain structures measured by Hertzian and Vickers indentation, J. Eur. Ceram. 35(2015) 1725-1736. 
[30] I.G. Batyrev, B.M. Rice, J.W. McCauley, First Principles Calculations of Nitrogen Atomic Position Effects on Elastic Properties of Aluminum Oxynitride AlON Spinel, Materials Research Society Fall Meeting. 2009 Paper No. LL5.3.

[31] X. Xie, W. Ying, J. Qi, et al, Gas-phase and solid-state simultaneous mechanism for two-step carbothermal AlON formation, J. Am. Ceram. Soc. 98(2015) 1965-1973.

[32] E.B. Tadmor, N.A. Bernstein, First-principles measure for the twinnability of FCC metals, J. Mech. Phys. Solids 52(2004) 2507-2519.

[33] S. Kibey, J.B. Liu, D.D. Johnson, et al, Predicting twinning stress in fcc metals: Linking twin-energy pathways to twin nucleation, Acta Mater. 55(2007) 6843-6851.

[34] J.W. Christian, S. Mahajan, Deformation twinning, Prog. Mater. Sci. 39(1995) 15 1-157.

[35] H.B. Zhao, H. Feng, F. Liu, et al., Effect of nanoscale twin and dislocation pileup at twin boundary on crack blunting in nanocrystalline materials, Acta Mater. 228(2017) 3483-3495.

[36] Y.T. Chou, T.W. Chou, J.C. Li. Screw dislocation pileups and shear cracks in a lamellar composite. J. Appl. Phys. 1970;41(11):4448-4450.

[37] E. El-Danaf, S.R. Kalidindi, R.D. Doherty, Influence of grain size and stacking-fault energy on deformation twinning in fcc metals, Metall. Mater. Trans. 30(1999) 1223-1233. 
[38] Y.T. Zhu, X.Z. Liao, X.L. Wu, et al., Grain size effect on deformation twinning and detwinning, J. Mater. Sci. 48(2013) 4467-4475. [39] K.M. Rahman, V.A. Vorontsov, D. Dye, The effect of grain size on the twin initiation stress in a TWIP steel, Acta Mater. 89(2015) 247-257. [40] S.A. Kibey, L.L. Wang, J.B. Liu, et al., Quantitative prediction of twinning stress in fcc alloys: Application to Cu-Al, Phys. Rev. B 79(2015) $1377-1381$.

[41] R.W. Rice, C.C. Wu, F. Boichelt, Hardness-grain-size relations in ceramics, J. Am. Ceram. Soc. 77(1994) 2539-2553.

[42] E.O. Hall, The Deformation and Ageing of Mild Steel: II Characteristics of the Luders Deformation, Proc. phys. soc. B 64(1951) 742.

[43] N.J. Petch, The cleavage strength of polycrystals, J. Iron. Steel. Inst. 174(1953) 25-28.

[44] MM. Ding, S. Robertson, T. Wang, L.C. Fan, et al., Characterization of micro-mechanical properties of AlON ceramic by cantilever bending test, J. Am. Ceram. Soc. 2019. https://doi. org/10.1111/jace.16614. 
Fig. 1 The XRD patterns of the synthetic AlON powders.

Fig. 2 SEM images of as-synthesized AlON powders through the $(a, b)$ SSR and (c,d) CRN methods.

Fig. 3 (a) and (b) BSE images and EBSD map of the as-polished cross-sectional surfaces of CRN-AlON powder; and (c) and (d) BSE images and EBSD map of the as-polished cross-sectional surfaces of SSR-AlON powder.

Fig. 4 (a) BSE images of the as-polished twin powder, (b) the lamina of the white square region prepared by FIB, (c, d) Conventional TEM images, (e, g) HRTEM images of twin boundary with SAED pattern insert and (f, h) corresponding inverse fast Fourier transform (IFFT) image, where label ' $T$ ' represents a dislocation.

Fig. 5 Euler + band contrast maps of the polished surface of CRN-AlON and SSR-AlON ceramics: (a) CRN-AlON without sintering additives, (b) SSR-AlON without sintering additives, (c) CRN-AlON and (d) SSR-AlON.

Fig. 6 EBSD maps of twins in powder: (a) IPF map, (c) Kernel Average Misorientation map, (c) image quality map and (d) elastic stress maps.

Fig. 7 EBSD maps of binary twins in ceramics: (a) IPF map, (c) Kernel Average Misorientation map, (c) image quality map and (d) elastic stress maps.

Fig. 8 EBSD maps of sandwich-like twins in ceramic: (a) IPF map, (c) 
Kernel Average Misorientation map, (c) image quality map and (d) elastic stress maps.

Fig. 9 The Vickers hardness in relation to the indentation load for CRN-AlON and SSR-AlON

Fig. 10 The calculated Vickers indentation fracture toughness as a function of the crack length for CRN-AlON and SSR-AlON.

Fig. 11 Representative crack propagation, deflection and resistance at grain or twin boundaries; red arrows indicate deflection, and yellow arrows represent resistance. 
Table 1. The Euler angles and misorientations of the AlON grains in Fig.

2

\begin{tabular}{|c|c|c|c|c|}
\hline \multirow{2}{*}{ Grain } & \multicolumn{3}{|c|}{ Euler angle $/^{\circ}$} & \multirow{2}{*}{ Misorientation } \\
\hline & $\psi$ & $\theta$ & $\varphi$ & \\
\hline \multirow{2}{*}{$\mathrm{T} 1$} & 217.1 & 17.8 & 186.4 & \multirow{2}{*}[11\overline{1}]{$/ 59.7^{\mathbf{o}}$} \\
\hline & 124.4 & 44.8 & 219 & \\
\hline \multirow{2}{*}{$\mathrm{T} 2$} & 157.9 & 28.8 & 210.9 & \multirow{2}{*}[11\overline{1}]{$/ 60^{\circ}$} \\
\hline & 318.5 & 42.6 & 55 & \\
\hline \multirow{2}{*}{$\mathrm{T} 3$} & 49.3 & 41.7 & 131.4 & \multirow{2}{*}[11\overline{1}]{$/ 59.7^{\circ}$} \\
\hline & 154.4 & 17.1 & 355.8 & \\
\hline \multirow{2}{*}{$\mathrm{T} 4$} & 4.9 & 19.7 & 204.1 & \multirow{2}{*}[\overline{1}11]{$/ 59.1^{\circ}$} \\
\hline & 289.3 & 51 & 218.5 & \\
\hline
\end{tabular}

Table 2. The Euler angles and corresponding misorientations of the selected grains in Fig. 4.

\begin{tabular}{|c|c|c|c|c|}
\hline \multirow{2}{*}{ Grain } & \multicolumn{3}{|c|}{ Euler angle/ ${ }^{\circ}$} & \multirow{2}{*}{ Misorientation } \\
\hline & $\psi$ & $\theta$ & $\varphi$ & \\
\hline \multirow{2}{*}{ BTA1 } & 71.77 & 45.75 & 299.91 & \multirow{2}{*}[\overline{1}\overline{1}1]{$/ 59.9^{\circ}$} \\
\hline & 156.16 & 24.32 & 188.86 & \\
\hline \multirow{2}{*}{ BTA2 } & 267.68 & 40.95 & 61.92 & \multirow{2}{*}[\overline{1}\overline{1}1]{$/ 59.3^{\circ}$} \\
\hline & 119.53 & 32.95 & 203.04 & \\
\hline \multirow{2}{*}{ STA1 } & 264.31 & 41.27 & 76.15 & \multirow{2}{*}[111]{$/ 59.8^{\circ}$} \\
\hline & 140.09 & 11.30 & 246.86 & \\
\hline \multirow{2}{*}{ STA1 } & 49.32 & 42.16 & 299.49 & \multirow{2}{*}[\overline{1}11]{$/ 60^{\circ}$} \\
\hline & 248.26 & 6.18 & 136.86 & \\
\hline \multirow{2}{*}{ BTB1 } & 92.90 & 34.10 & 130.20 & \multirow{2}{*}[11\overline{1}]{$/ 60^{\circ}$} \\
\hline & 216.80 & 20.80 & 336 & \\
\hline \multirow{2}{*}{ BTB2 } & 61.07 & 37.94 & 292.09 & \multirow{2}{*}[11\overline{1}]{$/ 59.7^{\circ}$} \\
\hline & 226.27 & 10.753 & 165.49 & \\
\hline \multirow{2}{*}{ STB1 } & 254.67 & 14.36 & 88 & \multirow{2}{*}[1\overline{1}\overline{1}]{$/ 59.9^{\circ}$} \\
\hline & 37.29 & 36.20 & 345.18 & \\
\hline \multirow{2}{*}{ STB2 } & 108.85 & 31.64 & 280.24 & \multirow{2}{*}[1\overline{1}\overline{1}]{$/ 59.9^{\circ}$} \\
\hline & 250.35 & 19.29 & 89.11 & \\
\hline \multirow{2}{*}{ BTC1 } & 27.07 & 40.04 & 305.12 & \multirow{2}{*}[1\overline{1}\overline{1}]{$/ 59.9^{\circ}$} \\
\hline & 188.87 & 315.59 & 147.01 & \\
\hline \multirow{2}{*}{ STC1 } & 161.06 & 19.39 & 202.11 & \multirow{2}{*}[1\overline{1}1]{$/ 59.9^{\circ}$} \\
\hline & 47.72 & 37.48 & 272.25 & \\
\hline \multirow{2}{*}{ BTD1 } & 351.99 & 38.19 & 334.55 & \multirow{2}{*}[1\overline{1}1]{$/ 59.9^{\circ}$} \\
\hline & 175.98 & 10.02 & 203.60 & \\
\hline
\end{tabular}




\begin{tabular}{lcccc}
\hline \multirow{2}{*}{ STD1 } & 20.80 & 36.44 & 306.80 & \multirow{2}{*}{$111] / 59.9^{\circ}$} \\
\hline
\end{tabular}

Table 3. The average grain sizes and twin densities of CRN-AlON and SSR-AlON ceramics.

\begin{tabular}{cccc}
\hline & Average Grain size & \multicolumn{2}{c}{ Twin Density $\left(\mathrm{m}^{-2}\right)$} \\
\cline { 3 - 4 } Materials & $(\mu \mathrm{m})$ & $\mathrm{BT}$ & $\mathrm{ST}$ \\
\hline CRN-AlON(-) & $105.24 \pm 8.25$ & $2.889 \times 10^{7}$ & $1.022 \times 10^{7}$ \\
CRN-AlON(+) & $112.31 \pm 5.77$ & $2.622 \times 10^{7}$ & $1.778 \times 10^{6}$ \\
SSR-AlON(-) & $106.28 \pm 7.51$ & $2.085 \times 10^{7}$ & $3.472 \times 10^{6}$ \\
SSR-AlON(+) & $121.32 \pm 5.14$ & $2.0 \times 10^{7}$ & $8.889 \times 10^{5}$ \\
\hline
\end{tabular}

+: with sintering adds, -: without sintering adds

Table 4. The parameters $n, A, a_{1}, a_{2}$ and $H_{P S R}$ determined in Meyer's law and the PSR model.

\begin{tabular}{lccccc}
\hline Materials & \multicolumn{2}{c}{ Meyer's law } & \multicolumn{3}{c}{ Proportional specimen resistance model } \\
\cline { 2 - 6 } & $\mathrm{n}$ & $\mathrm{A}$ & $\mathrm{a}_{1}$ & $\mathrm{a}_{2}$ & $\mathrm{H}_{\mathrm{PSR}}(\mathrm{GPa})$ \\
\hline SSR-AlON & 1.8444 & 0.0157 & 0.0572 & 0.0072 & 13.352 \\
CRN-AION & 1.8574 & 0.0159 & 0.0496 & 0.0079 & 14.650 \\
\hline
\end{tabular}




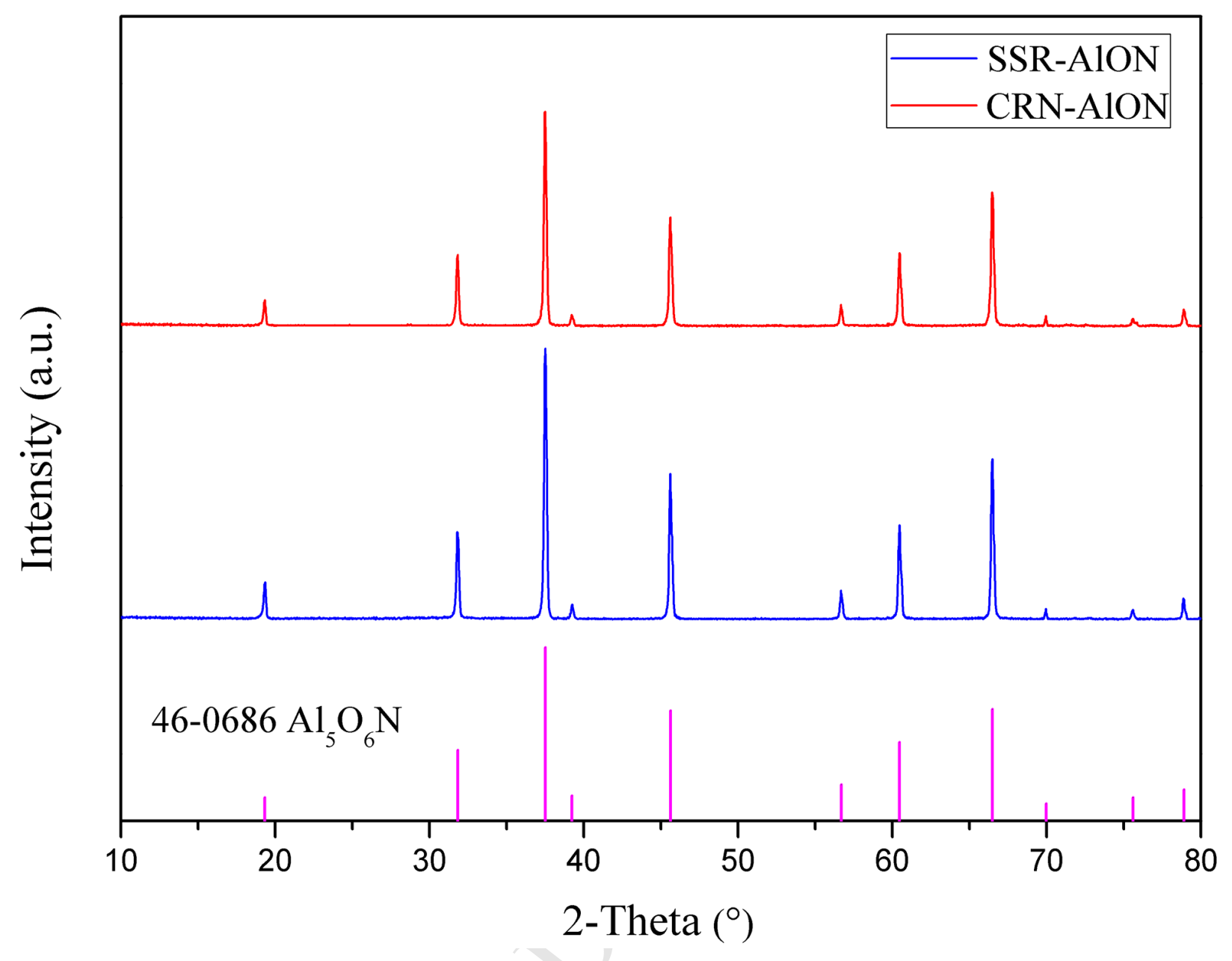




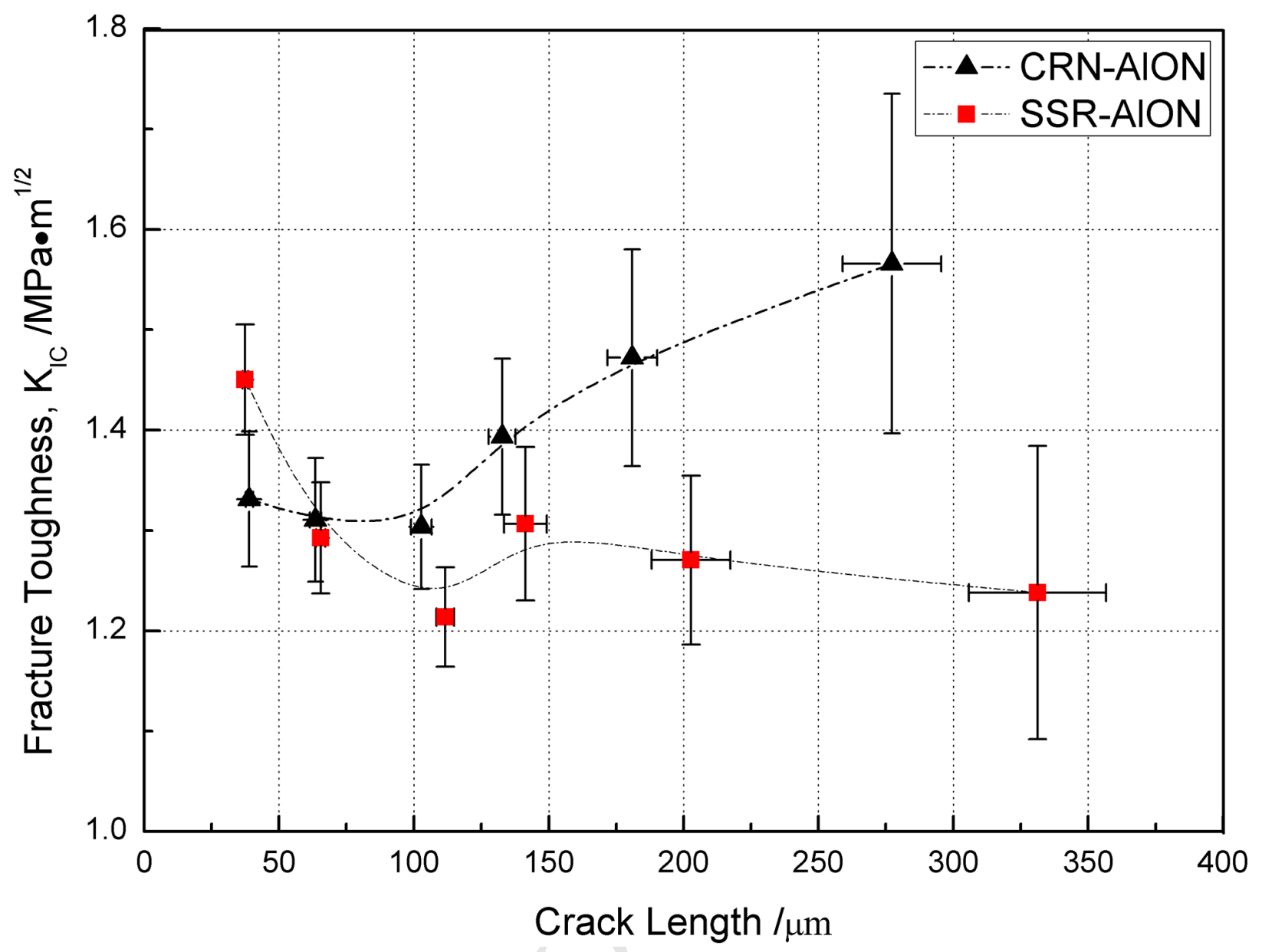



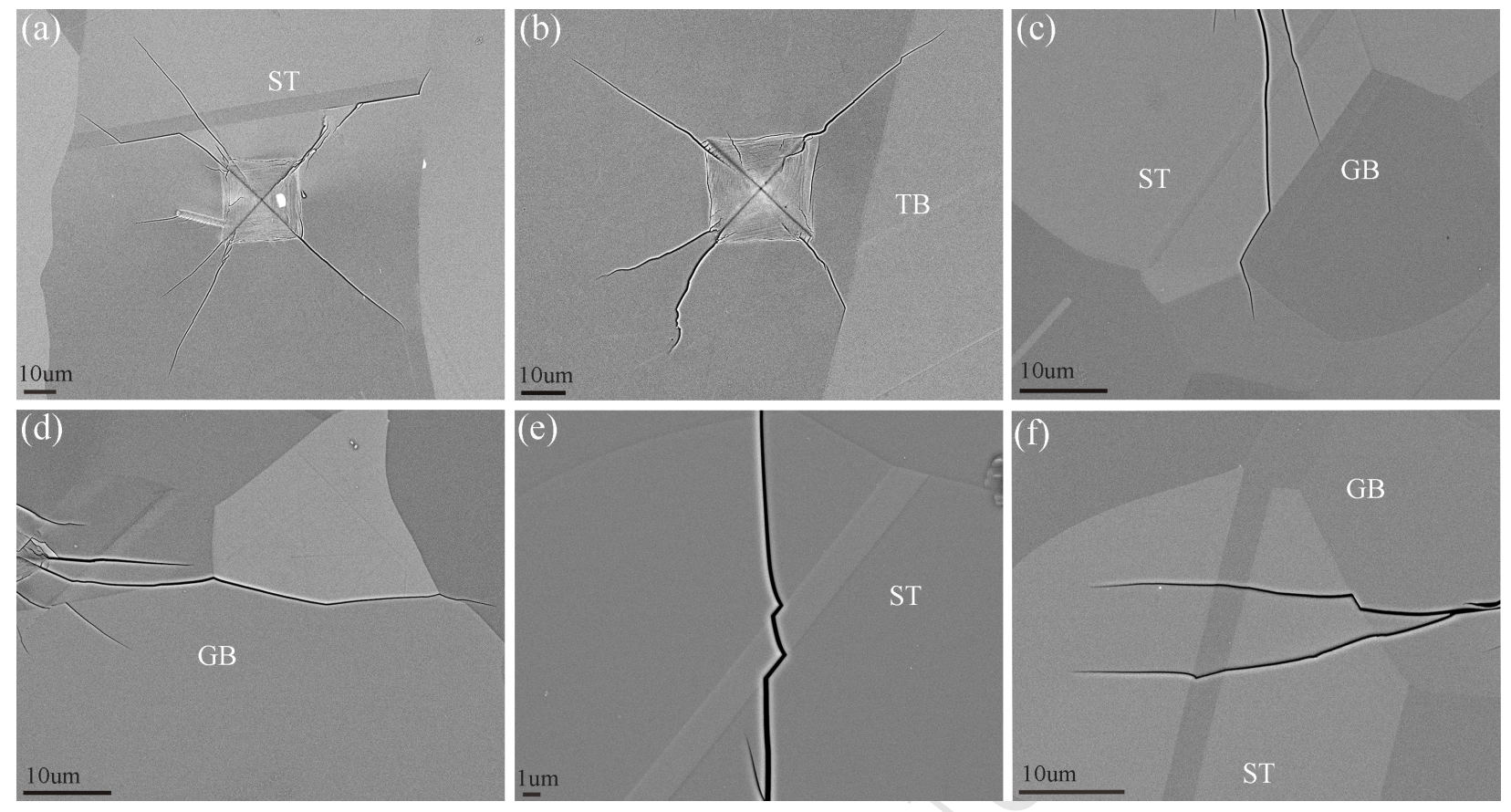

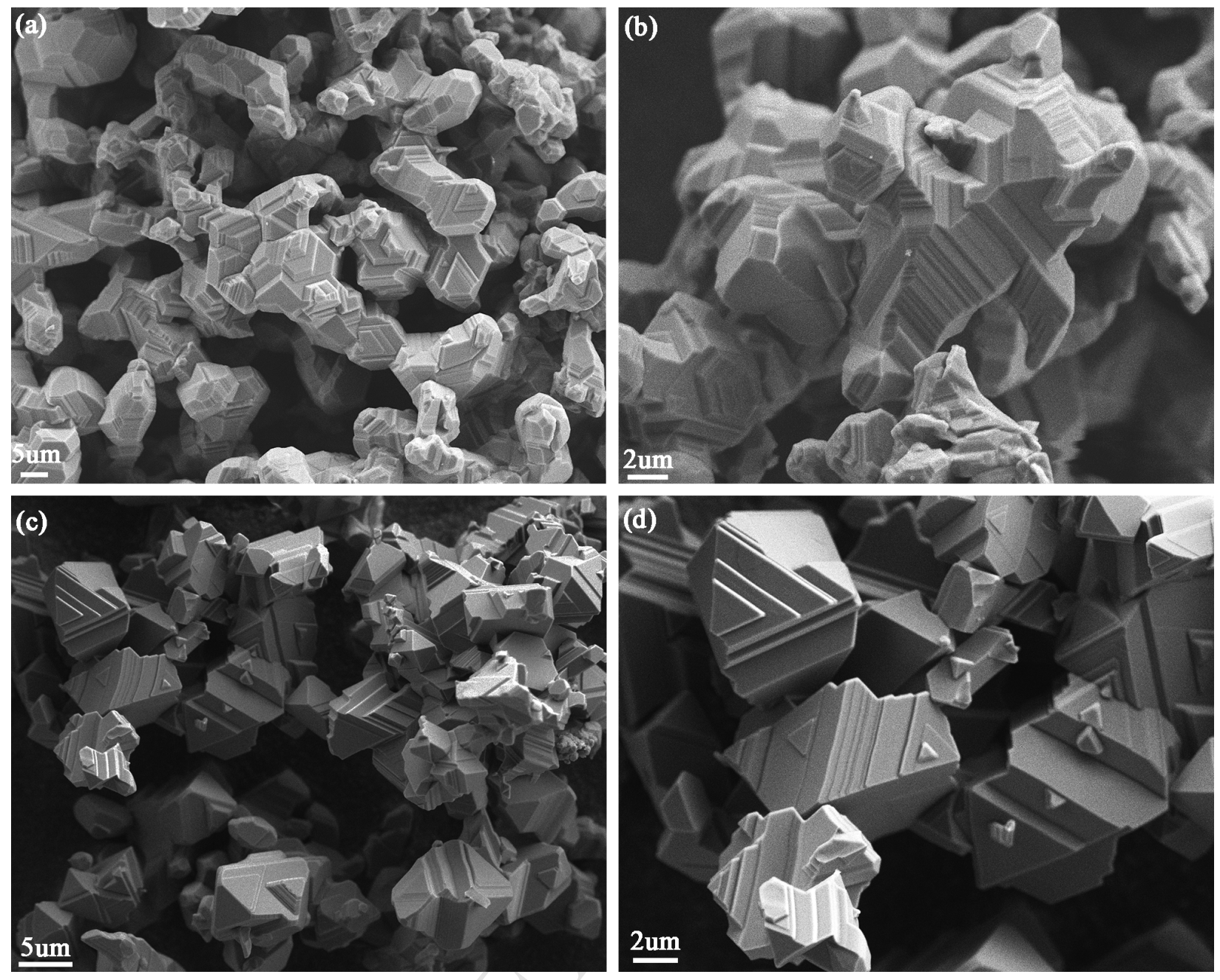


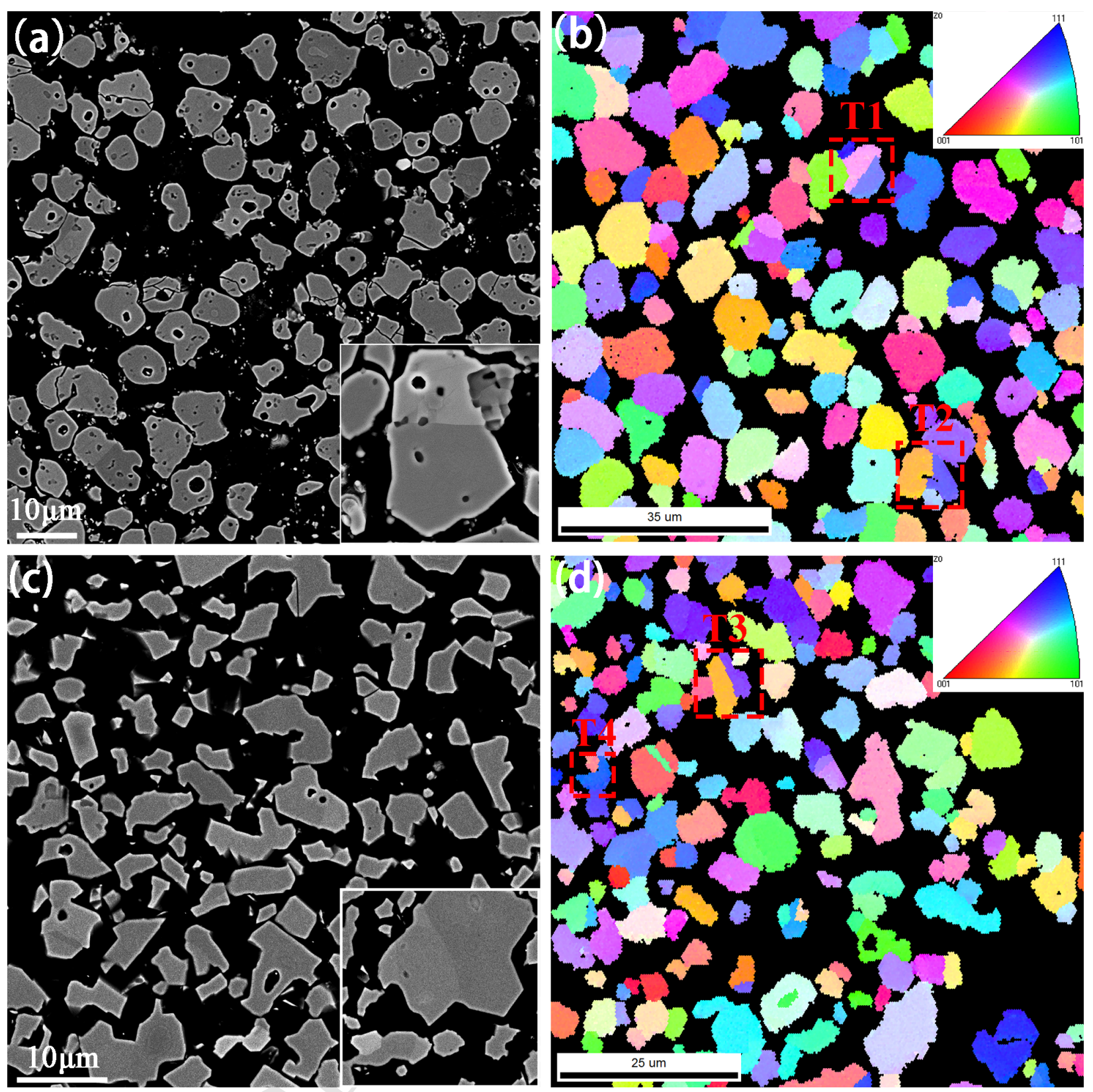




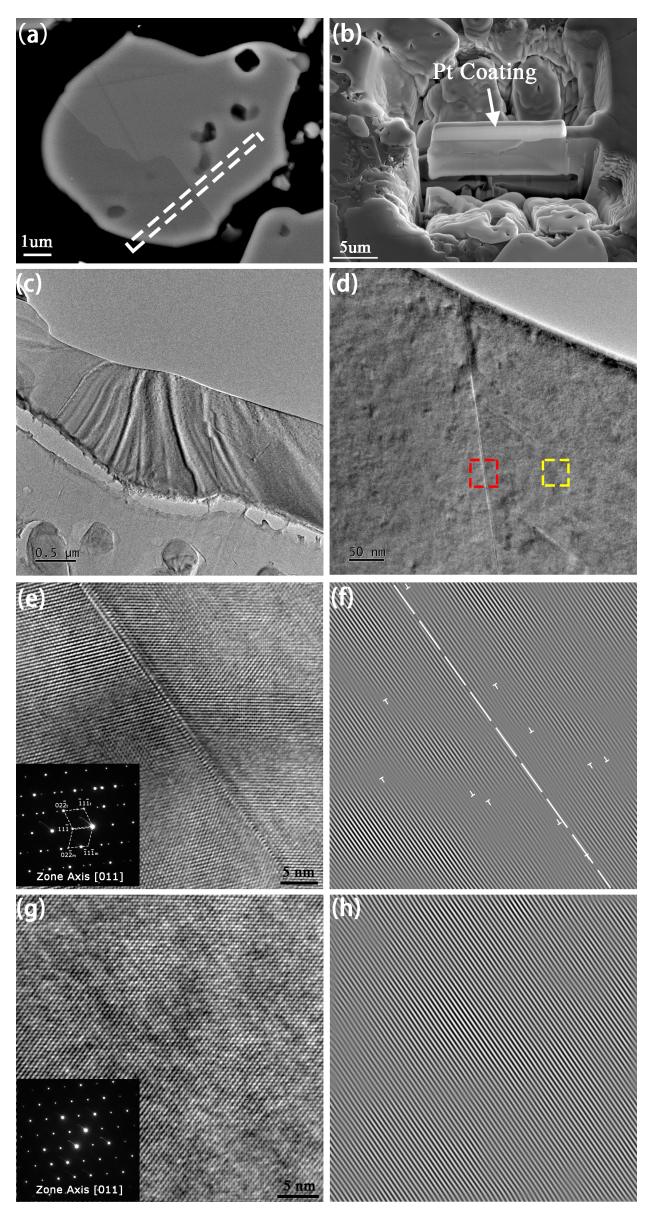



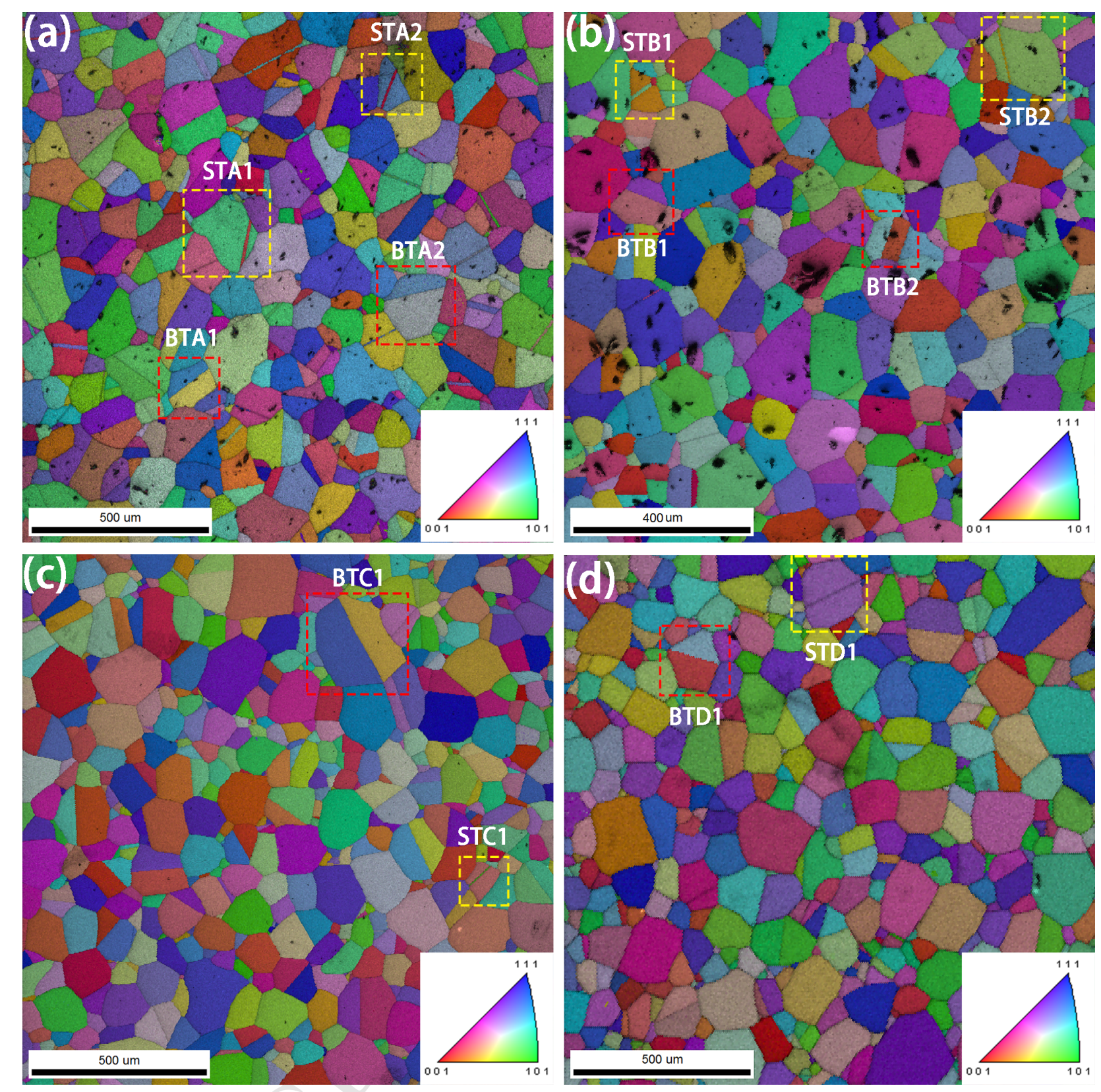
(a) [00010] 1 PPF

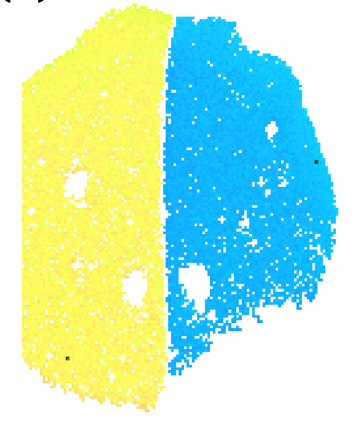

$-{ }_{2 \pi} \mu \mathrm{m}$

(d)

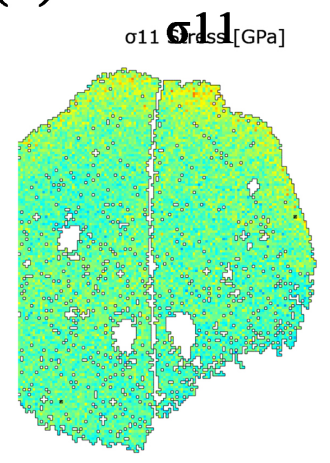

(b) Kernel AKaAMprientation
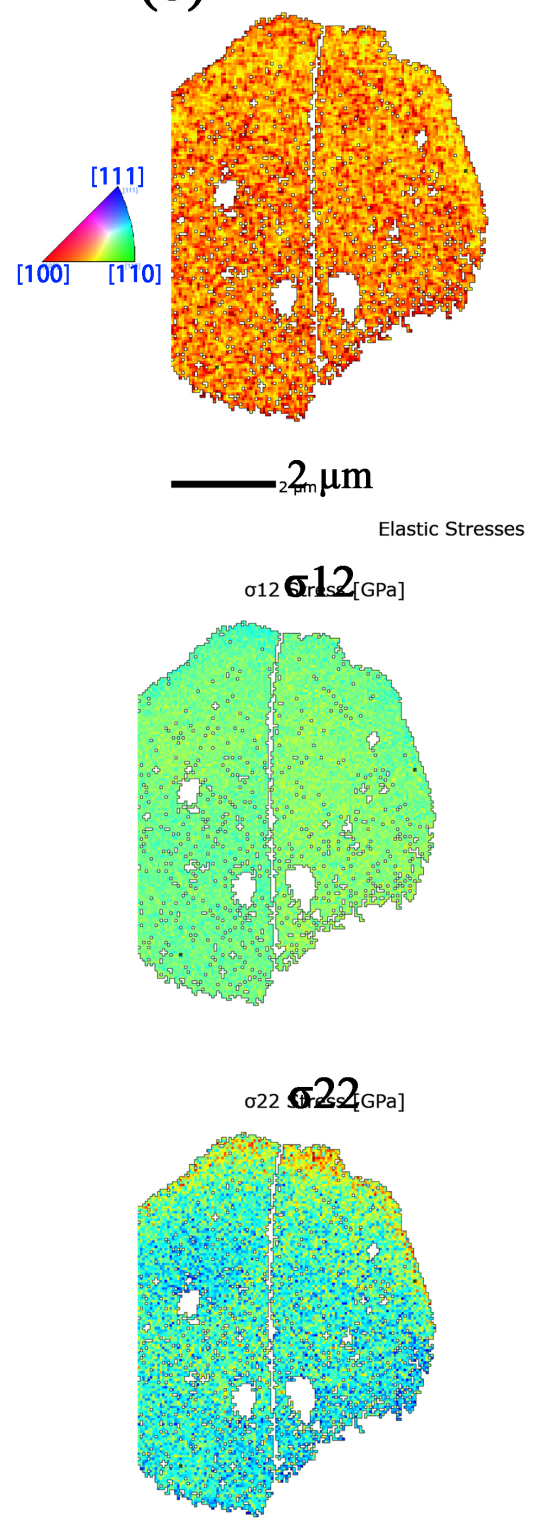

Von Misessstress

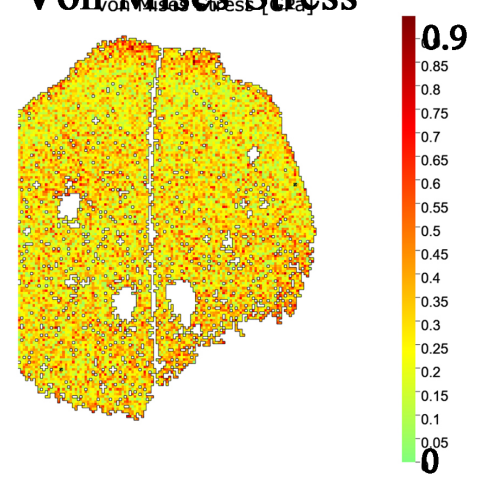

(c) Ba(quality

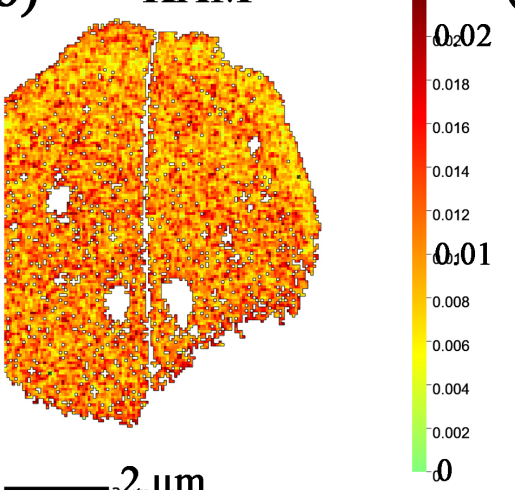

0
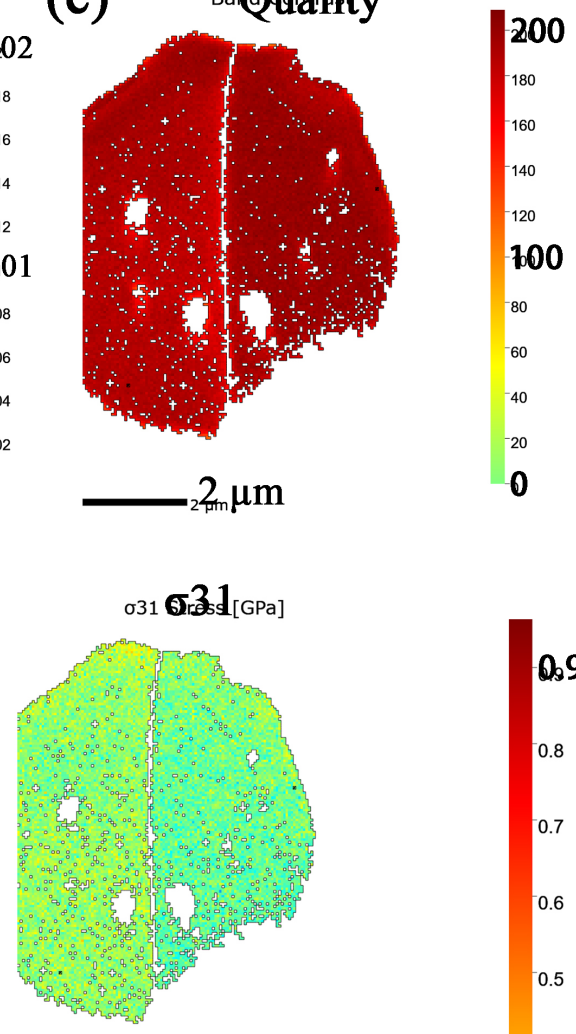

Q39 9

0.8

0.7

0.6

0.5

0.4

0.3

$-0.2$

0.1

0

$-0.1$

$-0.2$

$-0.3$

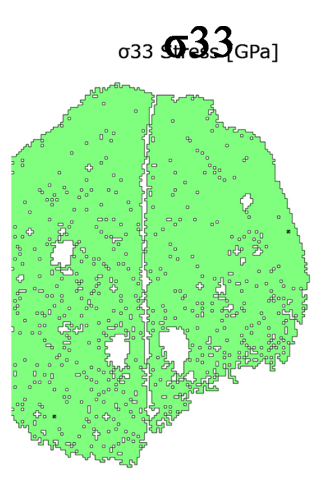

$-0.4$

$-0.5$

$-0.6$

$-0.7$

$-0.8$

$=0.9$ 

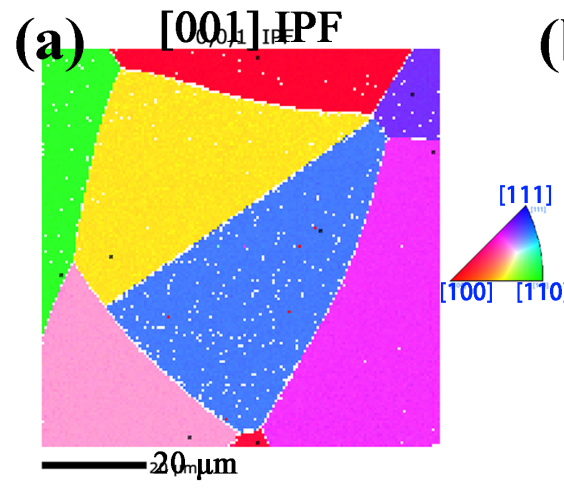

(b)
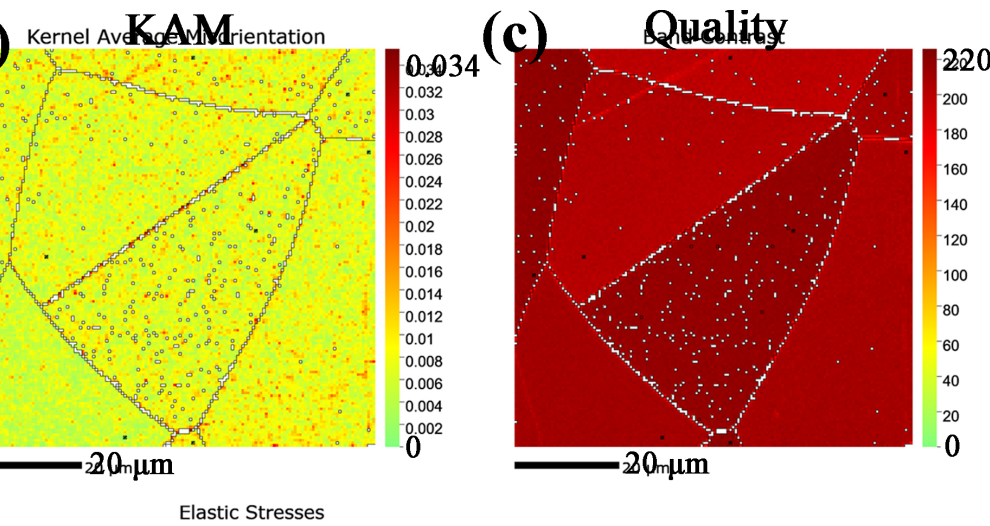

(d) ${ }_{\text {o11 }}$ erlst $_{[\mathrm{GPa}]}$
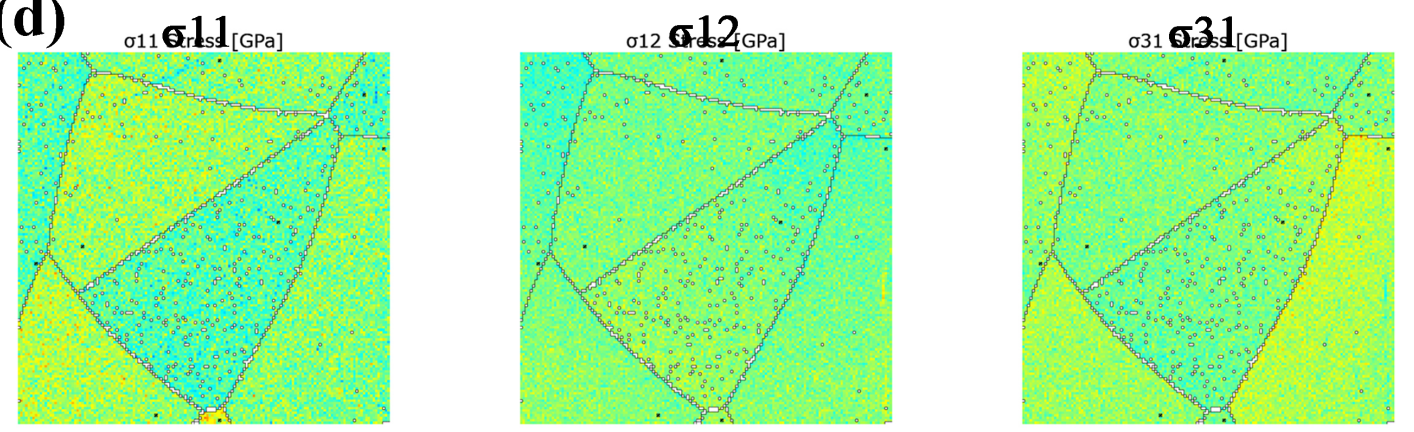

Q.45
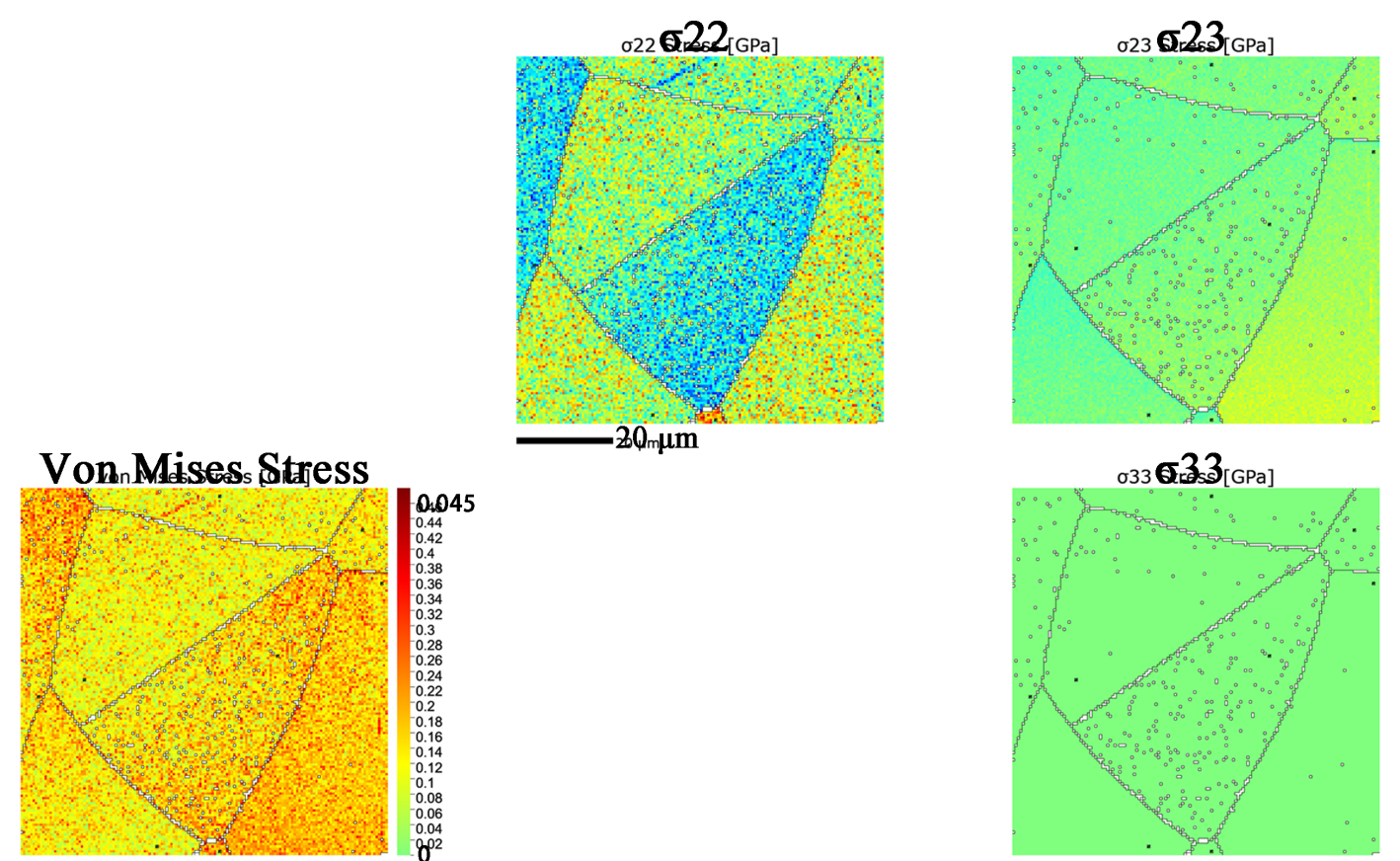

0.2
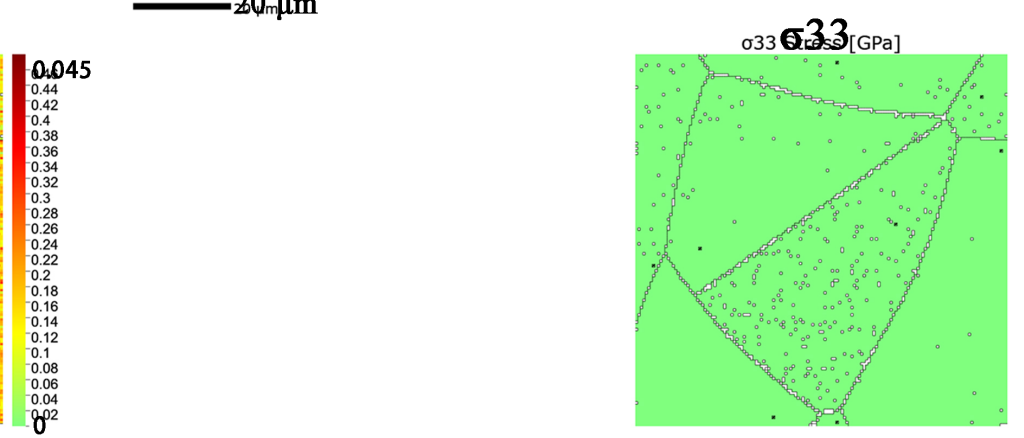
(a) $\left[0 Q, d_{1}\right]_{\mathrm{I}} \mathrm{IPF}$

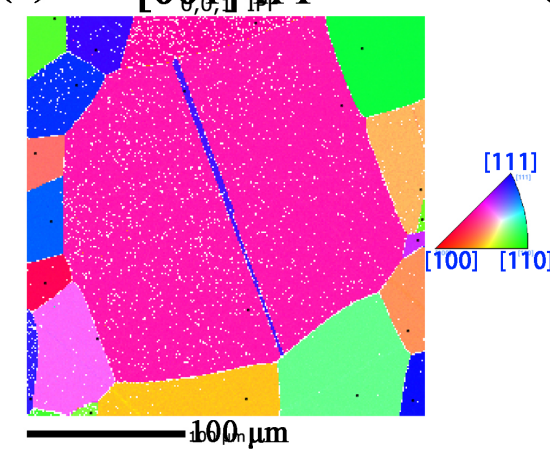

(d)

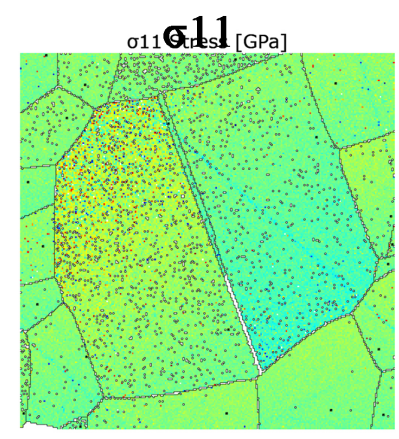

Von Mimsises Stress Stress

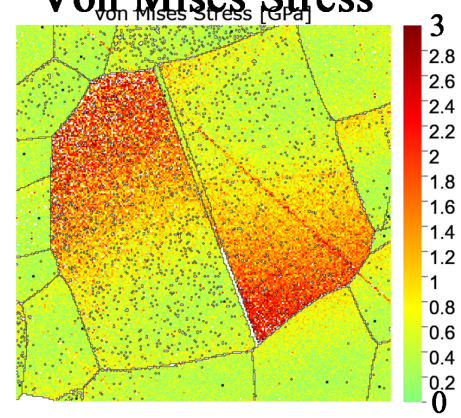

(b)

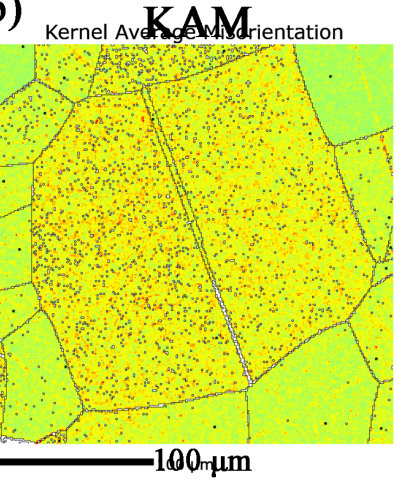

Elastic Stresses

${ }_{\mathrm{\sigma} 12} \mathrm{GH} 22_{\text {[GPa] }}$
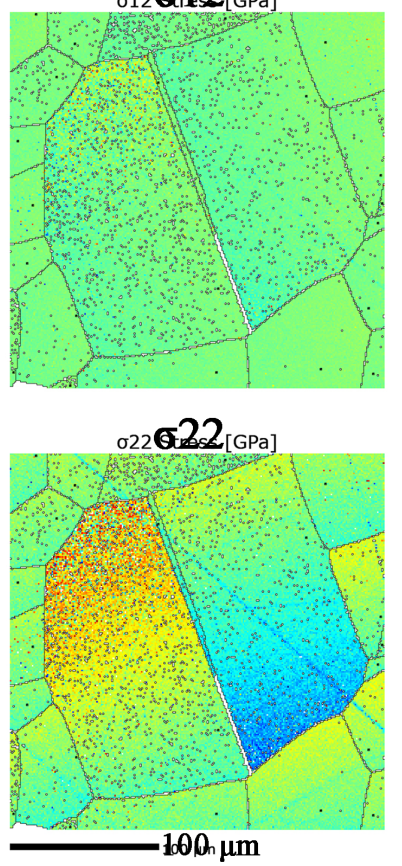

3
2.8
2.6
2.4
2.2
2
1.8
1.6
1.4
1.2
1
0.8
0.6
0.4
0.2
0 (c) Quality

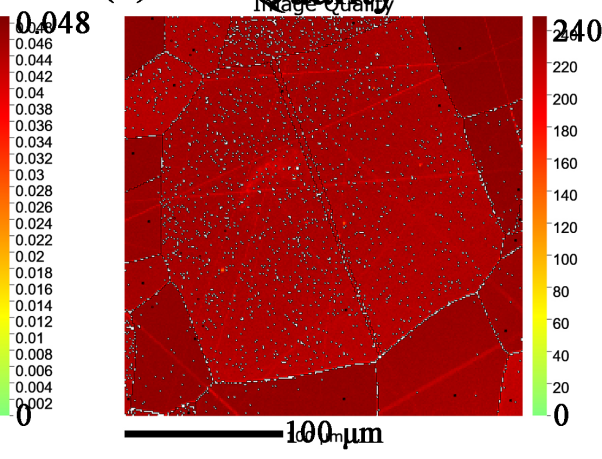

${ }_{031} \mathbf{C B}_{3} 1_{[\mathrm{GPa}]}$
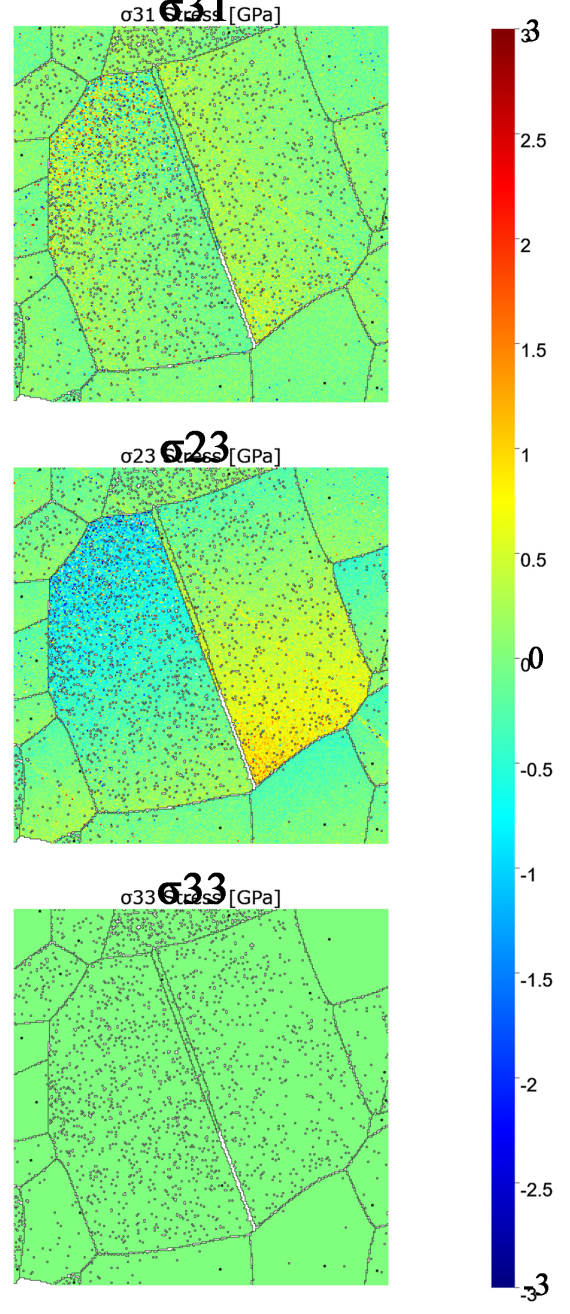


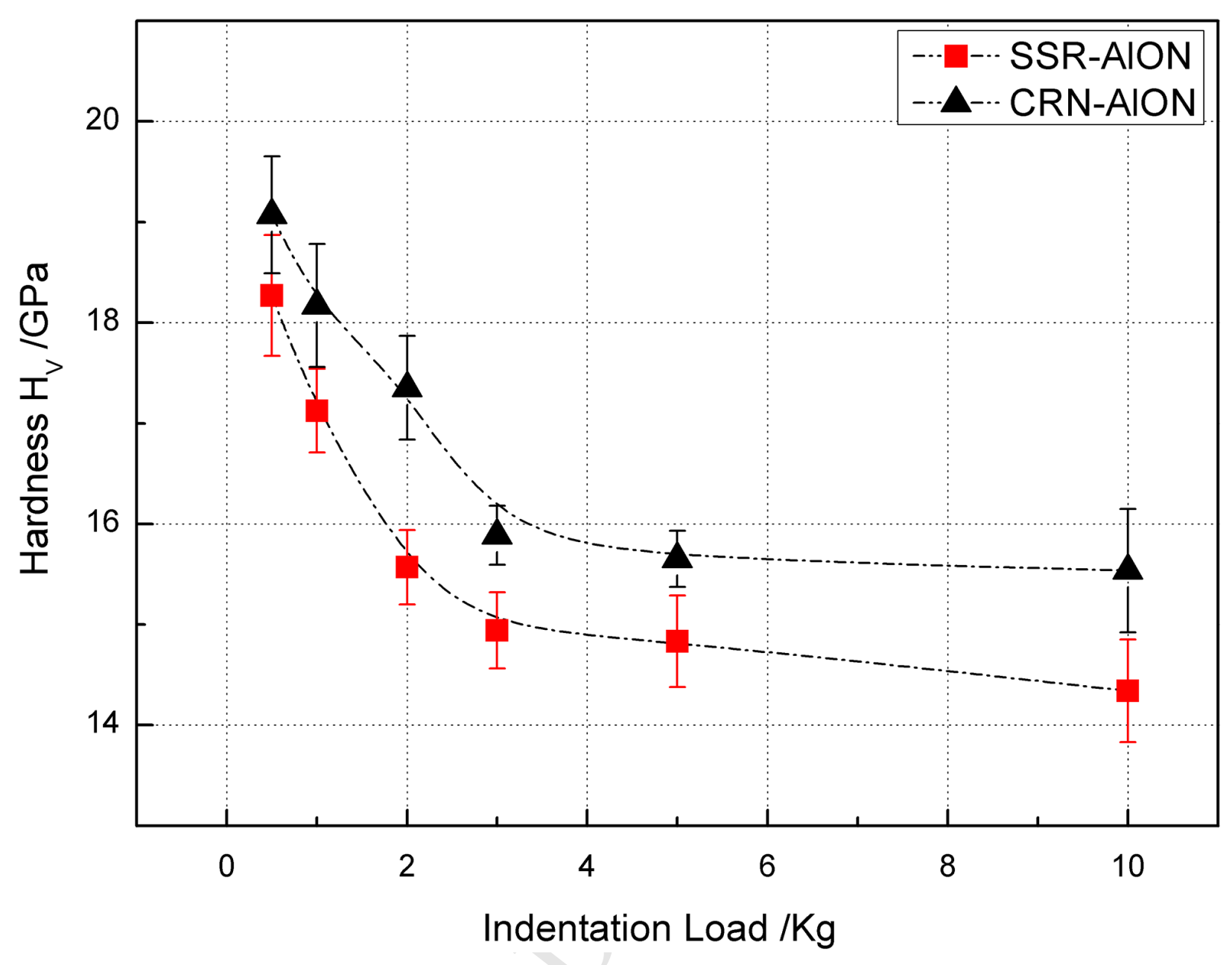

